\title{
Effect of 3 lactobacilli on immunoregulation and intestinal microbiota in a $\beta$-lactoglobulin-induced allergic mouse model
}

\author{
Guiming Fu, ${ }^{1,2}$ Kui Zhao, ${ }^{2}$ Hui Chen, ${ }^{2}$ Yuanyuan Wang, ${ }^{2}$ Lijuan Nie, ${ }^{3}$ Hua Wei, ${ }^{2,3}$ and Cuixiang Wan ${ }^{2,3 *}$ \\ ${ }^{1}$ Engineering Research Center for Biomass Conversion, Ministry of Education, Nanchang University, Nanchang, Jiangxi 330047, P. R. China \\ ${ }^{2}$ State Key Laboratory of Food Science and Technology, Nanchang University, Nanchang 330047, P. R. China \\ ${ }^{3}$ Sino-German Joint Research Institute, Nanchang University, Nanchang 330047, P. R. China
}

\section{ABSTRACT}

Milk is one of the earliest and most common allergen sources in the world, with $\beta$-lactoglobulin representing a major allergen protein. Numerous studies have reported that probiotics exert antiallergic and anti-inflammatory effects. Here, we examined the effects of 3 strains of Lactobacillus on immunomodulatory functions, intestinal barrier functions, and intestinal microbiota through a $\beta$-lactoglobulin-induced allergic mouse model. We found that the oral administration of Lactobacillus plantarum ZDY2013 and Lactobacillus rhamnosus GG suppressed allergic response, attenuating serum IgE and relieving anaphylaxis symptoms. The 3 strains of Lactobacillus could induce $\mathrm{T}$ helper (Th) 1 or T regulatory cells to differentiate to inhibit the Th2-biased response for regulating Th1/Th2 immune balance. Furthermore, L. plantarum ZDY2013 and L. rhamnosus GG enhanced intestinal barrier function through the regulation of tight junction. We also found that $L$. plantarum ZDY2013 and L. plantarum WLPL04 could regulate alterations in intestinal microbiota caused by allergies. In particular, Rikenella, Ruminiclostridium, and Lachnospiraceae UCG-006 were considerably reduced after treatment with L. plantarum ZDY2013 and L. plantarum WLPL04. These results suggested that 3 Lactobacillus strains may serve as an effective tool for the treatment of food allergies by regulating immune and gut microbiota.

Key words: Lactobacillus, food allergy, immunoregulation, intestinal microbiota

\section{INTRODUCTION}

Food allergy is a vital public health problem that affects adults and children, and its incidence has in-

Received September 12, 2018

Accepted November 26, 2018.

*Corresponding author: cuixiangwan@ncu.edu.cn creased considerably in recent decades (Neau et al., 2016). In Western countries, approximately 2 to $5 \%$ of children are affected by cow milk allergy (Shandilya et al., 2016), in which $\beta$-LG is the major allergen (BraunFahrländer and Von Mutius, 2011; Jo et al., 2014). To date, treatments for food allergies have been ineffective due to a lack of a clear understanding of the correlative molecular mechanisms. Therefore, the best remedy for the disease is to avoid exposure to food allergens (Hyung et al., 2017); however, accidental intake is difficult to completely avoid (Zhang et al., 2017).

Food allergies are mainly caused by allergens stimulating $\mathrm{CD} 4^{+} \mathrm{T}$ cells to differentiate into $\mathrm{T}$ helper $(\mathbf{T h})$ 2 cells, which produce IL-4, IL-5, and IL-13. These cytokines induce B cells to produce antigen-specific IgE antibodies, which combine with mast cells to stimulate mast cell degranulation and the release of histamine, prostaglandins, and leukotrienes, resulting in food allergy symptoms (Kaminogawa et al., 1999). However, the mechanism by which individuals respond to allergens remains uncertain.

The hygiene hypothesis is the first to link allergies to microbes, arguing that environmental changes are a major factor for the development of allergies (Strachan, 1989; Neau et al., 2016) and that improvement of hygiene conditions delays the establishment of microbes in infants, reduces stimulation of the body's immune system, and results in immature development of the body's immune system and immune function disorder, thereby leading to an increase in the incidence of food allergies and other allergic diseases (Gordon, 2011). The hygiene hypothesis supposes that moderate microbial stimulation plays an important role in establishing immune system maturation and oral tolerance (Nieuwenhuizen and Lopata, 2005). Therefore, intestinal commensal bacteria play a major role in promoting the maturation of the intestinal immune system and the delivery of mediators that trigger host immune and defense responses, regulating Th cell balance and acquisition of oral tolerance, and maintaining the integrity of intestinal epithelial cells (Slack et al., 2009; Chistiakov et al., 
2015; Fábrega et al., 2016). This intestinal microbiota disorder has been linked to increase the permeability of epithelial cells (Perrier and Corthesy, 2011; van Ree et al., 2014) and development of chronic inflammatory diseases, such as allergies and inflammatory bowel diseases (Artis, 2008; Tlaskalová-Hogenová et al., 2011; Penders et al., 2013).

In the study of allergic mechanisms, numerous probiotics have exhibited potential immunomodulatory effects. Despite cell limitations, the cell model performs an important position in the initial screening of different bacterial cells and bacterial metabolic components of immune response (Kobayashi et al., 2017). Numerous clinical reports have shown that probiotics can promote the differentiation of $\mathrm{T}$ regulatory (Treg) cell development and rebalancing Th1/Th2 responses to a Th1-dominant state (Forsythe, 2011; Kim et al., 2014). For example, Bifidobacterium infantis 14.518 screened from infant feces can potentially alleviate shrimp tropomyosin-induced allergy by tolerogenic dendritic cell-dependent induction of Treg cells and alterations in gut microbiota (Fu et al., 2017). Lactobacillus murinus NBRC14221 can modulate gut microbiota, intestinal $\mathrm{CD}_{11 \mathrm{c}^{+}}$cell functionality, and the Th1/Th2 immune balance against food allergy (Huang et al., 2016a). Furthermore, a mixture of Lactobacillus (Lmix) colonization improves the gut epithelial barrier and reduces allergic sensitization to Bet $\mathrm{v} 1$ through the increased production of circulating and secretory $\operatorname{IgA}$ and the regulatory cytokine transforming growth factor (TGF)- $\beta$ (Kozakova et al., 2016).

In recent reports, probiotics can regulate immune balance, improve intestinal barrier function (Vanderpool et al., 2008), and change the structure of intestinal microbiota, resulting in an effective alleviation of allergic responses (Delcenserie et al., 2008; Kwon et al., 2010; Diesner et al., 2016). For example, Lactobacillus fermentum CECT5716 can prevent intestinal barrier dysfunction in newborn rats (Vanhaecke et al., 2017). Bifidobacterium infantis can relieve food allergies by modulating the microbial population, and specific gut bacterial changes can play a substantial role in disease progression (Yang et al., 2017). Lactobacillus johnsonii BS15 can exert beneficial effects on intestinal microbiota and enhance intestinal immunity in healthy broilers as well as those afflicted with subclinical necrotic enteritis (Wang et al., 2018).

The effects of probiotics on the prevention or treatment of allergic diseases, such as atopic dermatitis, allergic rhinitis (AR), and food allergy (Ouwehand, 2007), have been studied. However, the underlying mechanisms are not fully understood, and different probiotics exhibit different capacities of immunomodulatory and regulating intestinal microbiota. The purpose of our study was to explore the effects of $L$. plantarum ZDY2013, L. plantarum WLPL04, and L. rhamnosus GG on immune regulation, intestinal barrier function, and intestinal microbiota through a $\beta$-LG-induced mice model and consequently provide theoretical support for the function of probiotics in preventing and alleviating allergic diseases.

\section{MATERIALS AND METHODS}

\section{Lactobacillus Strains and Culture Conditions}

Lactobacillus plantarum ZDY2013 isolated from homemade fermented soybeans (Huang et al., 2015), L. plantarum WLPL04 isolated from human breast milk (Jiang et al., 2016), and L. rhamnosus GG were cultured under anaerobic conditions at $37^{\circ} \mathrm{C}$ in sterile de Man, Rogosa, Sharpe broth (Beijing Solarbio Science \& Technology Co. Ltd., Beijing, China). Subsequently, lactobacilli were harvested, centrifuged at $5,000 \times g$ for $5 \mathrm{~min}$ at $25^{\circ} \mathrm{C}$, and washed in sterile PBS. The concentration of each suspension was adjusted to $10^{9} \mathrm{cfu} / \mathrm{mL}$.

\section{Animals and Housing Conditions}

Female BALB/c mice aged 6 to 8 wk were purchased from Jinan Peng Yue Experimental Animal Breeding Co. Ltd. (Jinan, China). All mice used in our study were cared for in accordance with the Guidelines for the Care and Use of Laboratory Animals published by the US National Institutes of Health (1996), and all experimental procedures were approved by the Animal Care Review Committee of Nanchang University. Animals were housed in an air-conditioned room $\left(23 \pm 2^{\circ} \mathrm{C}\right)$ with a 12-h light/12-h dark cycle. The mice were allowed free intake of food and purified water. All animal experiments were started after 1 wk of accumulation.

\section{Experimental Design}

Mice were randomly divided into a control group (C), sensitized group (M), and probiotics group (3 LAB). To induce an allergic response, mice were sensitized with $0.2 \mathrm{~mL}$ of $2 \mathrm{mg} / \mathrm{mL}$ allergen $(1 \mathrm{~mL}$ of Freund's adjuvant and $1 \mathrm{~mL}$ of $2 \mathrm{mg} / \mathrm{mL} \beta-\mathrm{LG}$ ) by i.p. injection on d 7, 14, 21, and 28 and challenged twice, which was stimulated once every $30 \mathrm{~min}$ with $\beta-\mathrm{LG}(5 \mathrm{mg} /$ mouse) on d 35. From d 7 to 35, mice in the 3 probiotic groups were administered $200 \mu \mathrm{L} /$ mouse of lactobacilli $\left[10^{9} \mathrm{cfu} / \mathrm{mL}\right.$ of L. plantarum ZDY2013 (ZDY2013 group), L. plantarum WLPL04 (WLPL04 group), or L. rhamnosus GG (LGG group)] in PBS by gavage, 4 times per week. Animals from the control and sensitized groups received $200 \mu \mathrm{L}$ of sterile PBS (Figure 1). 


\section{Evaluation of Anaphylaxis Reaction}

Anaphylaxis symptoms were scored by visually monitoring mice for $1 \mathrm{~h}$ after challenge. Anaphylactic symptoms were rated as $0=$ no symptoms; $1=$ hair up, scratching head and ear; $2=$ reduced activity, swelling around the eyes and mouth; $3=$ rest for more than a minute; $4=$ loss of consciousness, no activity upon prodding; and $5=$ convulsion, death (Li et al., 1999).

\section{Detection of IgE and Cytokines by ELISA}

The blood was taken from retro-orbital plexus on $\mathrm{d} 35$ and then centrifuged at $3,000 \times g$ for 20 min at $4^{\circ} \mathrm{C}$; the serum was then stored at $-80^{\circ} \mathrm{C}$ until used. Levels of serum total IgE, IFN- $\gamma$, IL-4, IL-17A, and TGF- $\beta$ were measured by ELISA according to the manufacturer's recommendations (NeoBioscience Co. Ltd., Shanghai, China).

\section{Histological Analysis}

Colon tissues of experimental mice were removed on d 35 and fixed in 10\% phosphate-buffered formalin and embedded in paraffin. The colon sections were stained with hematoxylin and eosin for observation of intestinal mucosal integrity and lymphocytic infiltration. All analyses were performed under a microscope at $200 \times$ magnification.

\section{Quantification of Cytokines and Tight Junction Protein Gene Expression in the Colon}

Quantitative analysis of II12a, Ifng, II4, II10, Tnf, Tbx21, Gata3, Rorc, Foxp3, Ocln, Cldn1, and Tjp1 in the mouse ileum tissues was performed by reverse transcription quantitative PCR. Total RNA was isolated from the tissue samples of the mouse colon using Takara MiniBEST Universal RNA Extraction Kit (Takara, Shiga, Japan) according to the manufacturer's protocol (He et al., 2017). We reverse transcribed RNA (500 ng) into cDNA using the Takara PrimeScriptTM RT reagent kit with gDNA Erase. Reverse transcription quantitative PCR was performed on an ABI Prism 7900HT sequence detection system (Applied Biosystems, Waltham, MA) using the following program: $30 \mathrm{~s}$ at $95^{\circ} \mathrm{C}$, followed by 40 cycles of $10 \mathrm{~s}$ at $95^{\circ} \mathrm{C}$, and $1 \mathrm{~min}$ at 58 to $62^{\circ} \mathrm{C}$. The sequences are listed in Table 1 . The housekeeping gene Gapdh was included for normalization.

\section{High-Throughput Sequencing and Bioinformatic Analysis}

The $16 \mathrm{~S}$ rRNA gene amplicon sequencing was performed on the Illumina MiSeq platform (Novogene Bioinformatics Technology Co. Ltd., Beijing, China) according to the previous report (Caporaso et al., 2011), which was used to determine sequences of the primers targeting the V4 hypervariable region of the bacterial $16 \mathrm{~S}$ rRNA genes $\left(515 \mathrm{~F}=5^{\prime}\right.$-GTGCCAGCMGCCGCGGTAA-3', 806R $=5^{\prime}$-GGACTACNNGGGTATCTAAT-3'). Bioinformatic analysis of sequencing data were analyzed using the Quantitative Insights Into Microbial Ecology (QIIME) software (Caporaso et al., 2011). Briefly, raw data from all samples were filtered and spliced to obtain high-quality clean reads. The effective tags were then clustered to operational taxonomic units (OTU) at an identity threshold of $97 \%$ similarity. Taxonomic ranks were assigned to OTU representative sequence using Ribosomal Database Project (RDP) Classifier v 2.2 (Cole et al., 2005). Finally, an OTU

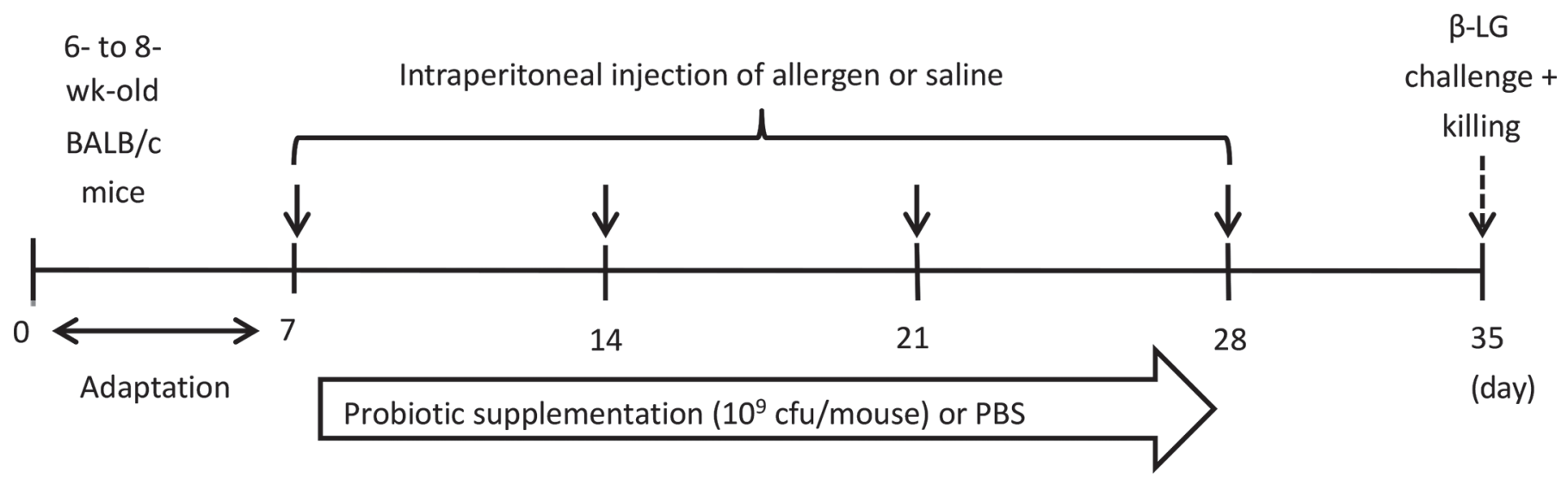

Figure 1. Experimental design of the mice model of food allergy to $\beta$-LG. Female BALB/c mice aged 6 to 8 wk were sensitized 4 times by intraperitoneal injection with $\beta$-LG (400 $\mu \mathrm{g} /$ mouse) plus Freund's adjuvant and challenged twice with $\beta$-LG (5 mg/mouse). In parallel, mice were orally supplemented with a probiotic strain or PBS for $4 \mathrm{wk}$. 
Table 1. Information of gene primers in the study

\begin{tabular}{|c|c|c|}
\hline Gene & Direction & Sequence $\left(5^{\prime}-3^{\prime}\right)$ \\
\hline \multirow[t]{2}{*}{ Gapdh } & Forward & CTGAACGGGAAGCTCACTGG \\
\hline & Reverse & ATGCCTGCTTCACCACCTTC \\
\hline \multirow[t]{2}{*}{ Tbx21 } & Forward & CCACCTGTTGTGGTCCAAGT \\
\hline & Reverse & CATTCGCCGTCCTTGCTTAG \\
\hline \multirow[t]{2}{*}{ Gata3 } & Forward & AAGCTCAGTATCCGCTGACG \\
\hline & Reverse & GTTTCCGTAGTAGGACGGGAC \\
\hline \multirow[t]{2}{*}{ Il12a } & Forward & AGTGACATGTGGAATGGCGT \\
\hline & Reverse & GGCGGGTCTGGTTTGATGAT \\
\hline \multirow[t]{2}{*}{ Il10 } & Forward & TTTGAATTCCCTGGGTGAGAA \\
\hline & Reverse & GCTCCACTGCCTTGCTCTTATT \\
\hline \multirow[t]{2}{*}{ Ifng } & Forward & GATCCTTTGGACCCTCTGACTT \\
\hline & Reverse & TGACTGTGCCGTGGCAGTAA \\
\hline \multirow[t]{2}{*}{$I_{4}$} & Forward & TCAACCCCCAGCTAGTTGTC \\
\hline & Reverse & TGTTCTTCGTTGCTGTGAGG \\
\hline \multirow[t]{2}{*}{$\operatorname{Tnf}$} & Forward & AGCCCACGTCGTAGCAAACC \\
\hline & Reverse & TACAACCCATCGGCTGGCAC \\
\hline \multirow[t]{2}{*}{ Rorc } & Forward & CCGCTGAGAGGGCTTCAC \\
\hline & Reverse & TGCAGGAGTAGGCCACATTACA \\
\hline \multirow[t]{2}{*}{ Foxp3 } & Forward & CAGCTGCCTACAGTGCCCCTAG \\
\hline & Reverse & CATTTGCCAGCAGTGGGTAG \\
\hline \multirow[t]{2}{*}{ Ocln } & Forward & GCTGTGATGTGTGTTGACTG \\
\hline & Reverse & CAAGGAGGTCCATCTGGCAG \\
\hline \multirow[t]{2}{*}{ Cldn1 } & Forward & GGGGACAACATCGTGACCG \\
\hline & Reverse & AGGAGTCGAAGACTTTGCACT \\
\hline \multirow[t]{2}{*}{ Tjp1 } & Forward & GATCCCTGTAAGTCACCCAGA \\
\hline & Reverse & CTCCСТGCTTGCACTCCTATC \\
\hline
\end{tabular}

table and a phylogenetic tree were produced according to $\alpha$ diversity (within a sample) and the $\beta$ diversity (between samples) analysis.

\section{Statistical Analysis}

Statistical significance was determined by GraphPad Prism5 (GraphPad Software, La Jolla, CA). All data are expressed as the mean \pm standard error of the means; $P$-values $<0.05$ were considered statistically significant.

\section{RESULTS}

\section{Lactobacillus Reduces $\beta$-LG-Induced Symptoms in a Mouse Model}

$\beta$-Lactoglobulin-induced food allergy symptoms were evaluated and scored for anaphylactic response. Severe symptoms of $\beta$-LG-induced food allergy were observed in the sensitized group (anaphylactic response, 2.67 \pm 0.82 points). By contrast, the ZDY2013 and LGG groups showed considerable suppression of anaphylactic response $(1.33 \pm 0.82$ and $1.25 \pm 0.71$ points, respectively, Figure 2A). In addition, the level of total $\mathrm{IgE}$ in the sensitized group increased by $15.95 \mathrm{ng} / \mathrm{mL}$ compared with that of the control group, but decreased by 4.43 and $3.01 \mathrm{ng} / \mathrm{mL}$ in the ZDY2013 and LGG groups, respectively (Figure 2B). The administration of ZDY2013 and LGG obviously inhibited $\beta$-LG-induced food allergy, suggesting a protective effect of Lactobacillus on food allergy in mice.

\section{Effect of Lactobacillus Supplementation on $T$ Cell Balance}

We measured the cytokine in serum from mice with $\beta$-LG-induced food allergy. Compared with the sensitized group, groups administered WLPL04 and LGG showed increased secretion of IFN- $\gamma$ in serum $(P<$ 0.05 ; Figure $3 \mathrm{~A})$. Interleukin-4, which is the major inducer of B-cell switching to IgE production (Akdis et al., 2011), was significantly decreased in groups treated with LGG $(P<0.05$; Figure 3B). Transforming growth factor- $\beta$, which is expressed by regulated dendritic cells, can directly mediate the conversion of $\mathrm{T}$ cells into Treg cells and induce immune tolerance (Kwon et al., 2010), and is significantly increased with ZDY2013 $(P<0.01)$ and LGG $(P<0.05$; Figure 3D). However, no evident changes of IL-17A (Figure 3C) were observed in the 3 Lactobacillus groups.

\section{Effect of Lactobacillus Administration on Th1/Th2/Th17/Treg Balance in the Colon}

The intestinal profile of the immune response induced by the administration of the 3 Lactobacillus strains was evaluated by analyzing the mRNA expression of Ifng, Il12, Il4, and Il10 (Figure 4). To further explore the 
effects of different Lactobacillus strains on Th responses in the colon, we measured the mRNA expression of Thspecific transcription factors (Figure 5). The expression of Tbx21 (Th1; $P<0.001$ ), Ifng, Il12, and Foxp3 (Treg; $P<0.001)$ was significantly decreased in the food allergy group compared with the control group, whereas the expression of Gata3 (Th2; $P<0.001$ ) and $I_{4}$ increased considerably. Supplementation with ZDY2013 induced a downregulation of the allergen-induced Th2 (Gata3; $P<0.001)$ and Th17 (Rorc; $P<0.001)$ responses but increased T-bet (Tbx21; $P<0.01)$ and IFN- $\gamma($ Ifng) at the colon. The expression levels of Gata3 $(P<0.001)$ and $I_{4} 4$ were significantly reduced with the administration of WLPL04, whereas the expression of Foxp3 $(P<$ $0.001)$ remarkably increased. With LGG treatment, the expression levels of Tbx21 (T-bet; $P<0.001$ ), Foxp3 ( $P$ $<0.05)$, Ifng, Il12, and Il10 were significantly increased. However, the expression of Gata3 $(P<0.001)$ and $I_{4}$ substantially decreased. To determine the extent of $\mathrm{Th}$ response skewing in the colon, we calculated the ratios for Gata3/Tbx21 (Th2/Th1) and Foxp3/Rorc (Treg/ Th17) mRNA expression. We observed a Th2-skewed immune response in the sensitive groups as represented by a significant increase in Gata3/Tbx21 ratio compared with the control group; ZDY2013, WLPL04, and LGG reduced this ratio.

\section{Effects of the Colonization of 3 Lactobacillus Strains on Intestinal Barrier Function}

Intestinal barrier function is crucial in maintaining homeostasis; the destruction of barrier function can lead to intestinal disorders, such as leaky gut syndrome, inflammatory bowel disease, and food allergy. Although the change in intestinal permeability by the destruction of barrier function is considered a risk factor in the development of food allergy, this hypothesis has yet to be substantiated with experimental data (Chahine and Bahna, 2010). Therefore, we explored whether Lactobacillus can regulate intestinal barrier function in our mouse model of food allergy by measuring the tight junction proteins claudin-1 (Cldn1), occludin-1 (Ocln), and ZO-1 (Tjp1) in the colon (Figure 6). We found decreased transcriptional expression of claudin-1 and occludin-1 in $\beta$-LG-induced mice, whereas the expression levels of claudin-1 and occludin-1 were restored after administration of ZDY2013 and the expression level of occludin-1 increased after supplementation with LGG. However, no changes in the relative levels of ZO-1 mRNA expression were observed with probiotic strain treatment. These results suggest that enhancement of tight junction protein mRNA expression might contribute to the attenuation of food allergy.
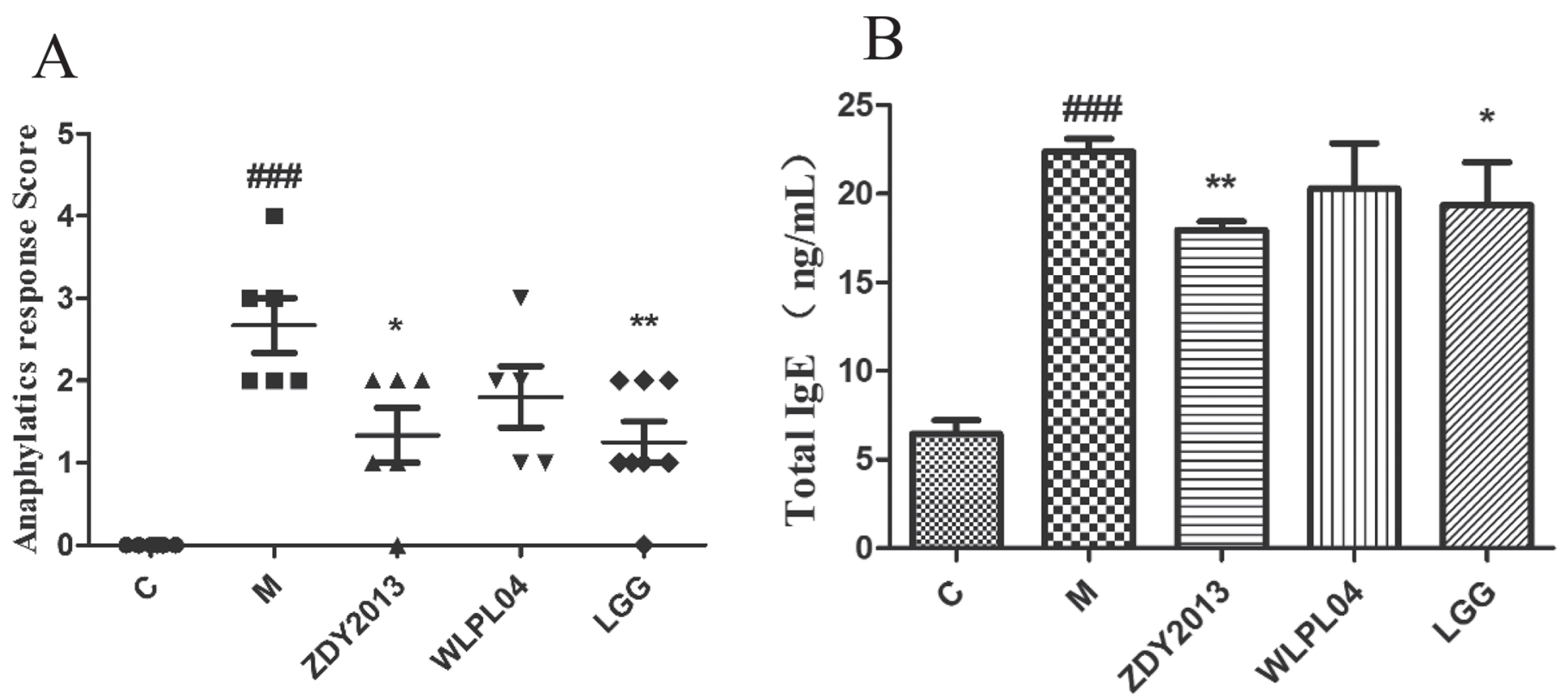

Figure 2. Lactobacillus reduced $\beta$-LG-induced symptoms in a mouse model of food allergy: (A) anaphylactic response and (B) level of total IgE. Mice were treated from d 7 to 35 with $200 \mu \mathrm{L}$ of L. plantarum ZDY2013 (ZDY2013 group), L. plantarum WLPL04 (WLPL04 group), or L. rhamnosus GG (LGG group). The results are expressed as the mean \pm SD; $P$-values determined by one-way ANOVA followed by Tukey's post hoc test. Significant differences of the sensitized (M) group versus the control (C) group are indicated as \#\#\#P<0.001. Significant differences of ZDY2013, WLPL04, and LGG group versus M group are indicated as ${ }^{*} P<0.05$, ${ }^{* *} P<0.01$. 


\section{Three Lactobacillus Strains Reduce Histological Changes in Allergic Mice}

Hematoxylin and eosin staining visualized histological changes, such as mucosal or crypt damage and lymphocyte infiltration. Here, the sensitive group showed that intestinal epithelium and goblet cells were severely damaged in comparison with the control group. By contrast, the 3 Lactobacillus treatment group showed similar results to those of control mice (Figure 7).

A

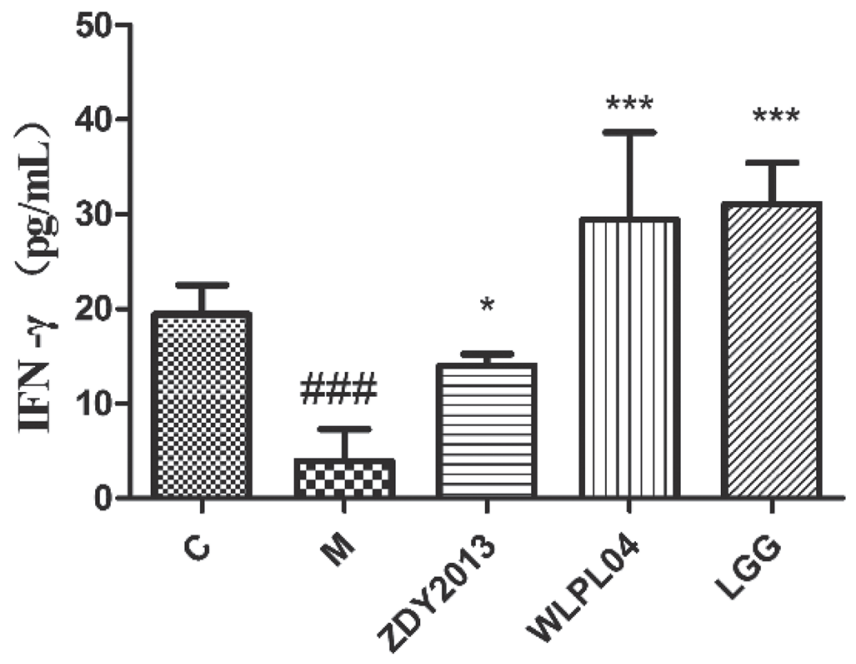

C

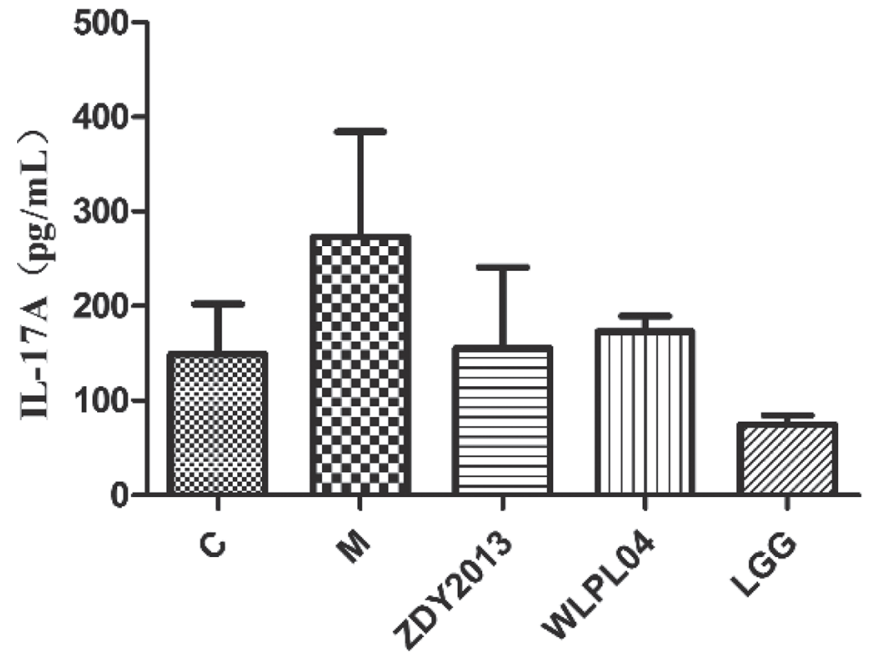

Three Lactobacilli Modulate Fecal Microbiota Composition in $\beta-L G-I n d u c e d$ Mice

We further performed $\alpha$ and $\beta$ analyses of fecal microbiota composition of the 5 groups. The rarefaction curve is shown in Figure 8A, whereas the intestinal bacterial composition of the 5 groups is shown in Figure 8B. Four phyla (in descending order: Firmicutes, Bacteroidetes, Proteobacteria, and Actinobacteria) were the most dominant; among 10 bacterial phyla,

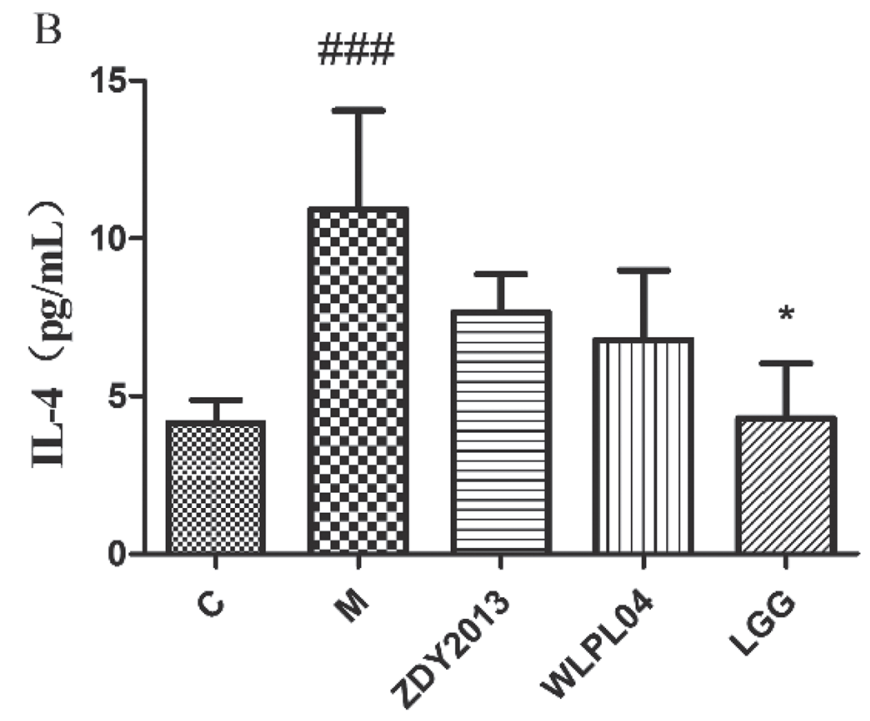

D

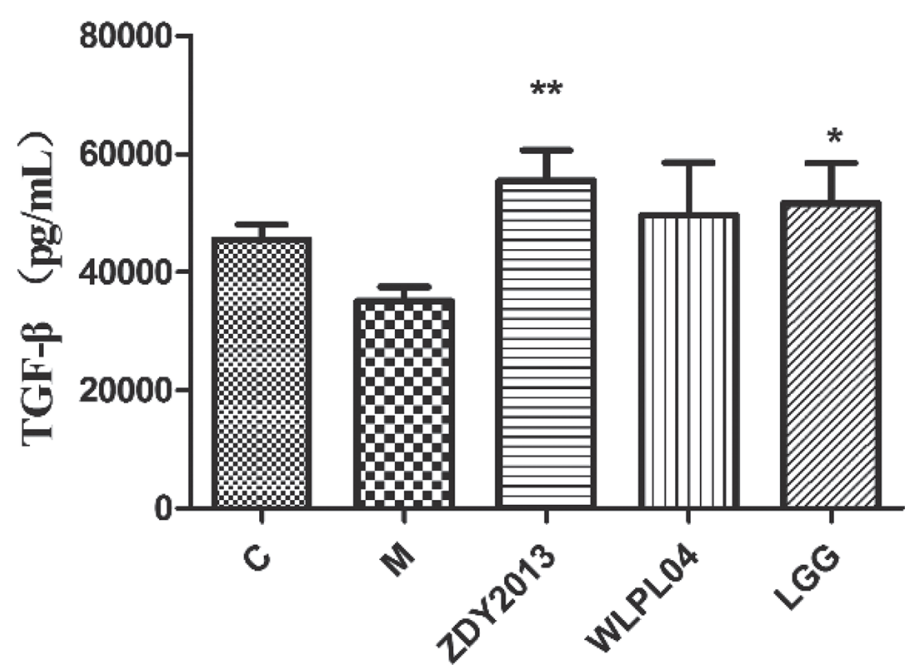

Figure 3. Effect of probiotic treatment on ex vivo cytokine secretion of serum from mice with $\beta$-LG-induced food allergy. Serum was collected after oral challenge of $\beta$-LG twice. Cytokine secretions were determined by ELISA. Mice were treated from d 7 to 35 with $200 \mu \mathrm{L}$ of $L$. plantarum ZDY2013 (ZDY2013 group), L. plantarum WLPL04 (WLPL04 group), or L. rhamnosus GG (LGG group). Results are expressed as means \pm SD for (A) IFN- $\gamma$, (B) IL-4, (C) IL-17A, and (D) transforming growth factor (TGF)- $\beta$. Significant differences of the sensitized (M) group versus the control $(\mathrm{C})$ group are indicated as \#\#\#P<0.001. Significant differences of ZDY2013, WLPL04 and LGG group versus M group are indicated as $* P<0.05,{ }^{* *} P<0.01,{ }^{* * *} P<0.001$. 

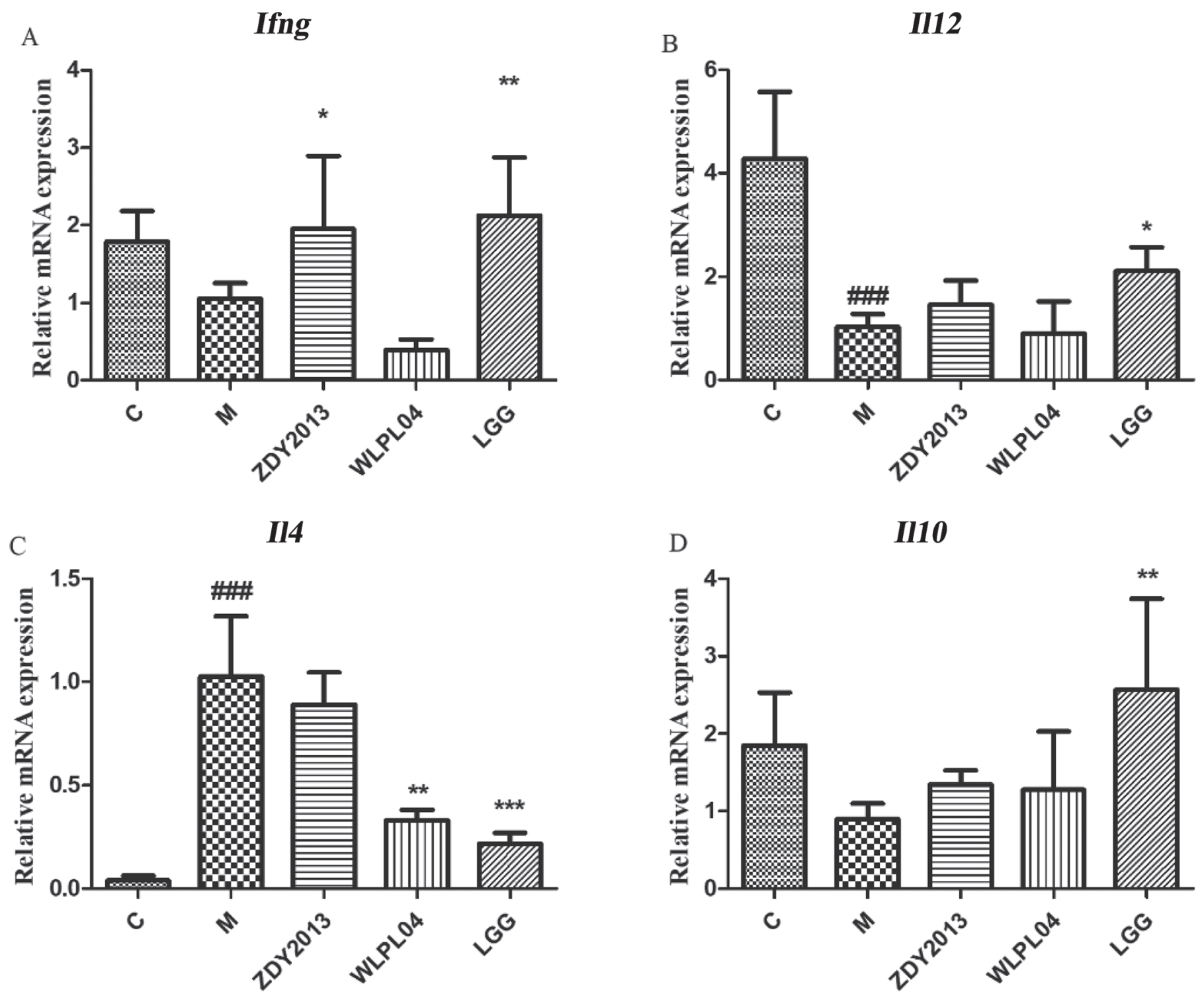

Figure 4. Effect of probiotic treatment on the colon tissue of the immune response. Colon gene mRNA expression was quantified by reverse transcription quantitative PCR. Mice were treated from d 7 to 35 with $200 \mu \mathrm{L}$ of L. plantarum ZDY2013 (ZDY2013 group), L. plantarum WLPL04 (WLPL04 group), or L. rhamnosus GG (LGG group). Results are expressed as means \pm SD for (A) Ifng, (B) Il12, (C) Il4, and (D) Il10. Significant differences of the sensitized (M) group versus the control (C) group are indicated as \#\#\#P<0.001. Significant differences of ZDY2013, WLPL04 and LGG group versus M group are indicated as ${ }^{*} P<0.05,{ }^{* *} P<0.01, * * * P<0.001$.

Firmicutes and Bacteroidetes accounted for an average of $87.76 \%$ of each sample's OTU. The changes in fecal microbiota across groups were examined by using principal coordinates analysis (PCoA) and unweighted pair-group method with arithmetic means (UPGMA) cluster. Similar PCoA distances were observed among ZDY2013 group and control groups compared with sensitized group (Figure 8C); UPGMA cluster analysis showed that ZDY2013 significantly changed the intestinal microbiota compared with $\beta$-LG-induced sensitized mice (Figure 8D).
Taxonomic assignment revealed marked differences between the control group and sensitized group (Table 2 ). At the family level, 4 bacterial families (Lactobacillaceae, Enterococcaceae, Erysipelotrichaceae, and Clostridiales vadin BB60 group) were much more abundant in the sensitized group. We identified 6 bacterial genera, including Lactobacillus, Enterococcus, Rikenella, Ruminiclostridium, unidentified Ruminococcaceae, and unidentified Lachnospiraceae. We found that the abundance at the genus level of 4 taxa (Rikenella, Ruminiclostridium, unidentified Ruminococcaceae, and un- 

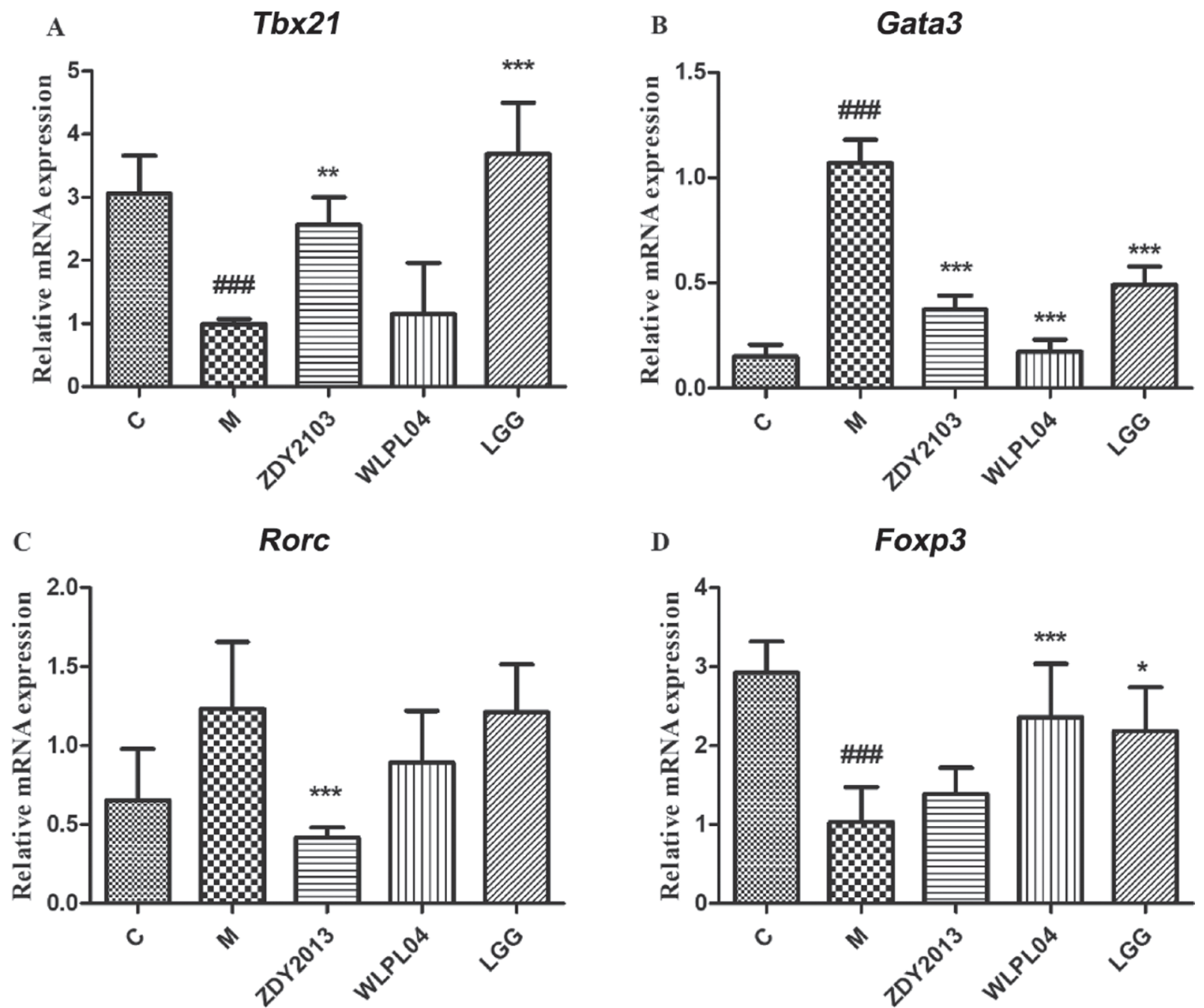

D

Foxp3

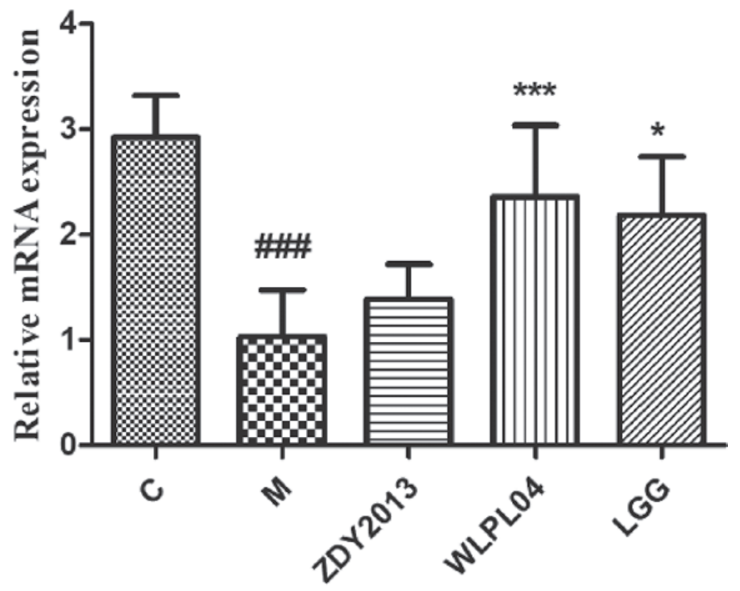

E

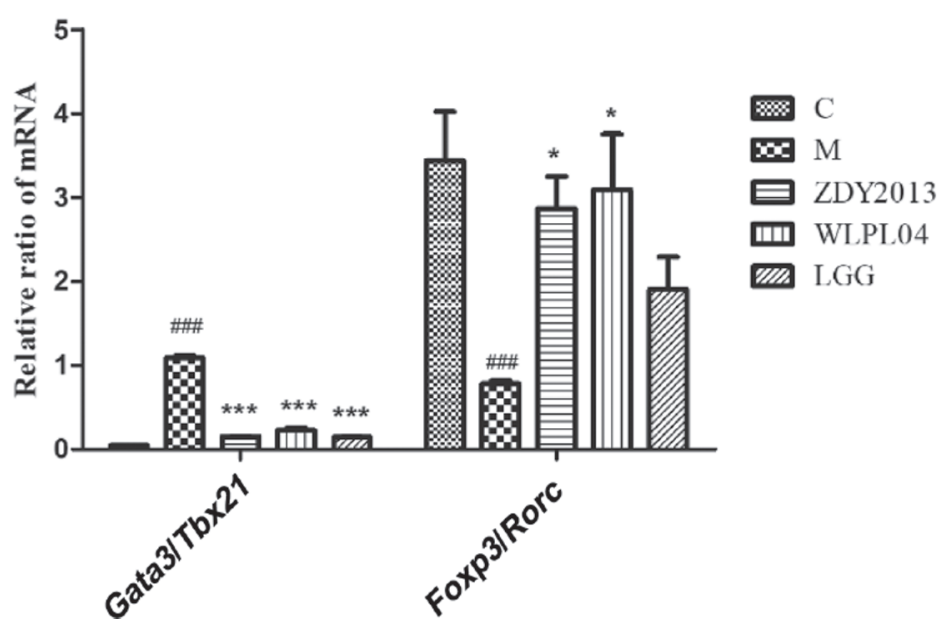

Figure 5. Effect of probiotics on relative expression of transcriptional regulation factors in colonic tissue. Colon gene mRNA expression was quantified by quantitative PCR. Mice were treated from d 7 to 35 with $200 \mu \mathrm{L}$ of L. plantarum ZDY2013 (ZDY2013 group), L. plantarum WLPL04 (WLPL04 group), or L. rhamnosus GG (LGG group). Results are expressed as means \pm SD for (A) Tbx21, (B) Gata3, (C) Rorc, (D) Foxp3, and (E) Gata3/Tbx21 and Foxp3/Rorc. Significant differences of the sensitized (M) group versus the control (C) group are indicated as \#\#\#P<0.001. Significant differences of ZDY2013, WLPL04, and LGG group versus M group are indicated as ${ }^{*} P<0.05,{ }^{* *} P<0.01,{ }^{* * *} P$ $<0.001$. 
A

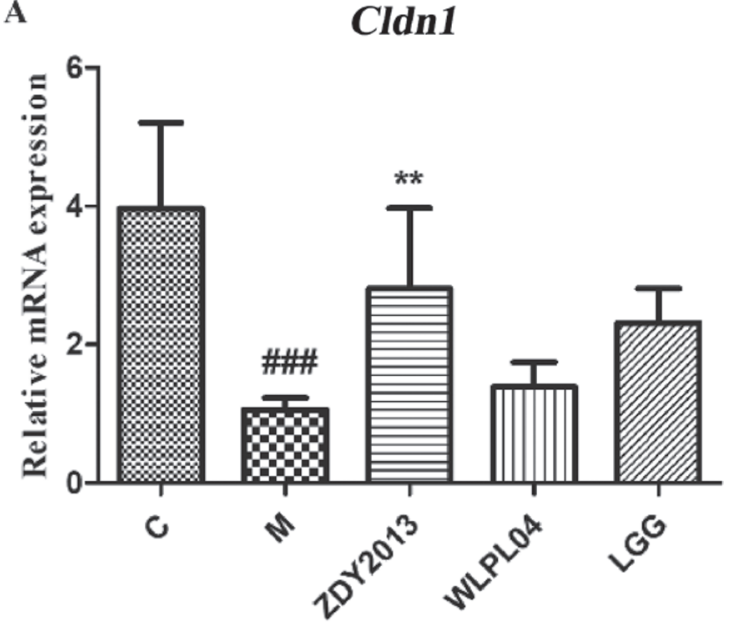

B

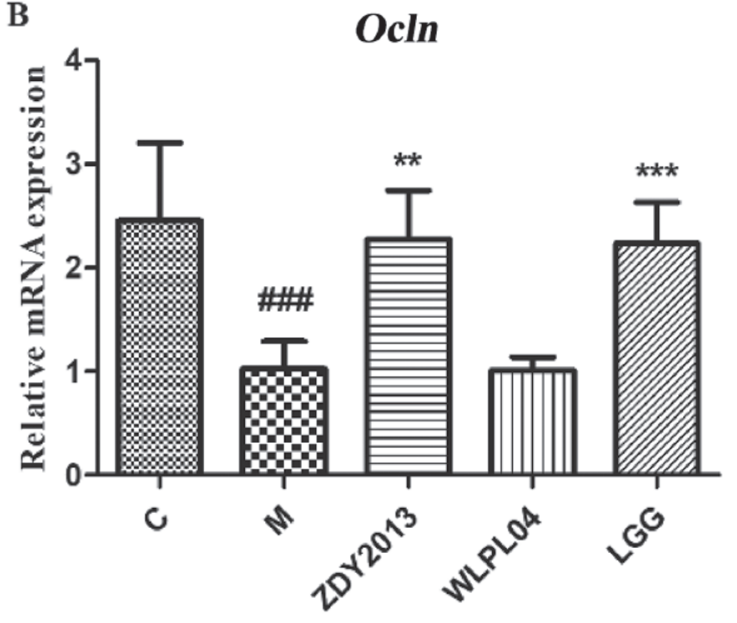

C

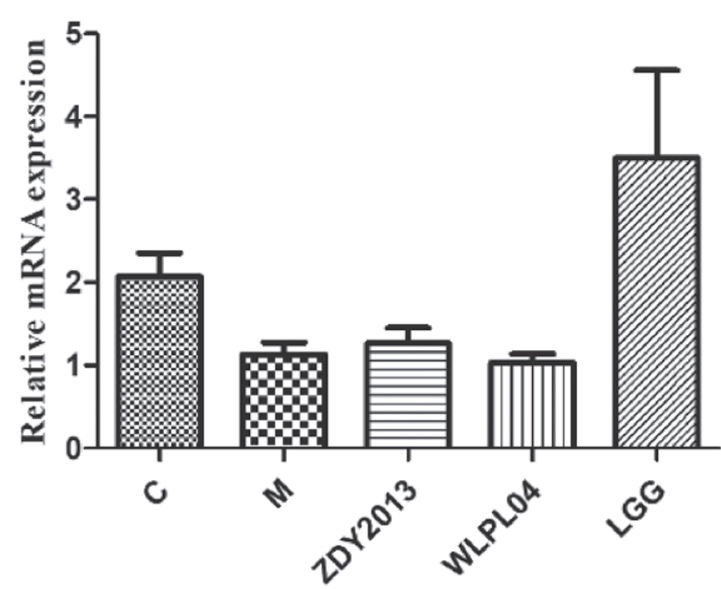

Figure 6. Effect of probiotics on relative expression of intestinal barrier function in colonic tissue. Colon gene mRNA expression was quantified by quantitative PCR. Results are expressed as means \pm SD for (A) claudin-1 (Cldn1), (B) occludin-1 (Ocln), and (C) zonula occludens-1 (Tjp1). Significant differences of the sensitized (M) group versus the control $(\mathrm{C})$ group are indicated as \#\#\#P<0.001. Significant differences of ZDY2013, WLPL04, and LGG group versus $\mathrm{M}$ group are indicated as ${ }^{* *} P<0.01,{ }^{* * *} P<0.001$.

identified Lachnospiraceae) decreased in the ZDY2013 (Table 3) and WLPL04 groups (Table 4). Supplemental Figure S1 (https://doi.org/10.3168/jds.2018-15683) shows Shannon and Simpson indices of $\alpha$-diversity.

\section{DISCUSSION}

Probiotics play a significant role in regulating allergic reactions. A probiotic mixture can be effective in redirecting allergen-specific Th2-polarized immune responses toward Th1-Treg responses and in protection against anaphylactic reactions induced by the allergen of food allergy (Schiavi et al., 2011). Lactobacillus rhamnosus CGMCC 1.3724 and peanut oral immunotherapy effectively prevented peanut allergy in clinical trials (Tang et al., 2015). A Bifidobacteria mixture can notably improve AR symptoms and quality of life in children with pollen-induced AR and intermittent asthma (Miraglia Del Giudice et al., 2017). Although the administration of probiotics is proven an effective tool for alleviating allergies in experiments, different probiotics enact different mechanisms of action to allergic reactions. We explored the effect of 3 strains of Lactobacillus on $\beta$-LG-induced allergy; among these strains, L. plantarum ZDY2013 and L. plantarum WLPL04 performed numerous probiotic functions, such as acid resistance and antiadhesion of pathogens (Huang et al., 2016b; Jiang et al., 2016) through a mouse model. Supplementation with the ZDY2013 and LGG strains led to a considerable decrease in serum IgE, which is associated with Th2 and the important indicator in allergy reactions. Meanwhile, allergic reactions of mice, such as erection of hairs, edema around the eyes and mouth, and other symptoms, were substantially alleviated, as observed previously (Zhang et al., 2017).

Transcriptional regulatory factors such as T-bet, GATA-3, ROR- $\gamma$ t, and Foxp-3 are responsible for helper $\mathrm{T}$ cell subsets differentiated from naïve T cells (Lin et al., 2015). To investigate the reactive mechanism of the 3 Lactobacillus strains, we explored their effects on immunoregulation in the colonic tissues of sensitized mice. Mice administered 3 strains of Lactobacillus exhibited Th2 resistance, and the expression of GATA-3 markedly decreased; GATA-3 is a key molecule that regulates the balance in the ratio Th1 cells and Th2 cells and is considered to be indicative of the pathogenesis of allergic diseases (Bae et al., 2011). Meanwhile, ZDY2013 and LGG induced colon expression of T-bet and regulated the differentiation of Th1. Both WLPL04 and LGG induced the expression of Foxp-3, which is a main regulator of functional differentiation of Treg cells (Pellerin et al., 2014) that can induce and maintain immune tolerance by inhibiting Th2 differentiation (Cottrez et al., 2000). Reports showed that 
Foxp-3 might inhibit allergic reaction by controlling the degranulation of mast cell (Gri et al., 2008).

Transforming growth factor- $\beta$ and IL-10 are Tregrelated cytokines that are essential for maintaining immune tolerance and reducing allergic reactions (Huang et al., 2010). Moreover, IFN- $\gamma$ and IL-12 secreted by Th1 cells can inhibit the differentiation of Th2 cells and relieve allergies (Kirjavainen et al., 1999). Studies have reported that the use of probiotic strains can promote the differentiation of Th1 and Treg, which perform important roles as adjunctive treatments for allergic diseases. Studies showed that the LGG strain can induce the production of IFN- $\gamma$ and IL-10 and relieve skin symptoms in IgE-sensitized infants with atopic dermatitis (Pessi et al., 2000; Pohjavuori et al., 2004). In the present study, TGF- $\beta$ increased after oral administration with ZDY2013 and LGG, whereas IFN- $\gamma$ considerably increased after oral administration of WLPL04 and LGG. Therefore, we speculate that $L$. plantarum ZDY2013 and L. rhamnosus GG can alleviate allergies by inducing the Th1 or Treg cell response.

Numerous studies reported that imbalances in the body's immune system result from food allergies and increased intestinal permeability (Bae et al., 2016; Kozakova et al., 2016; Neau et al., 2016). The increase in intestinal permeability and disruption of intestinal barrier function are known risk factors for developing food allergy (Chahine and Bahna, 2010). Studies have shown that food allergies increase intestinal permeability not only in children but also in asthma patients (Järvinen et al., 2013). In our study, the mRNA expression of tight junction proteins (e.g., claudin-1 and occludin-1) significantly increased after treatment with ZDY2013. These results were consistent with the findings of NébotVivinus et al. (2014), which showed that multispecies probiotics can enhance occludin-1 expression to prevent
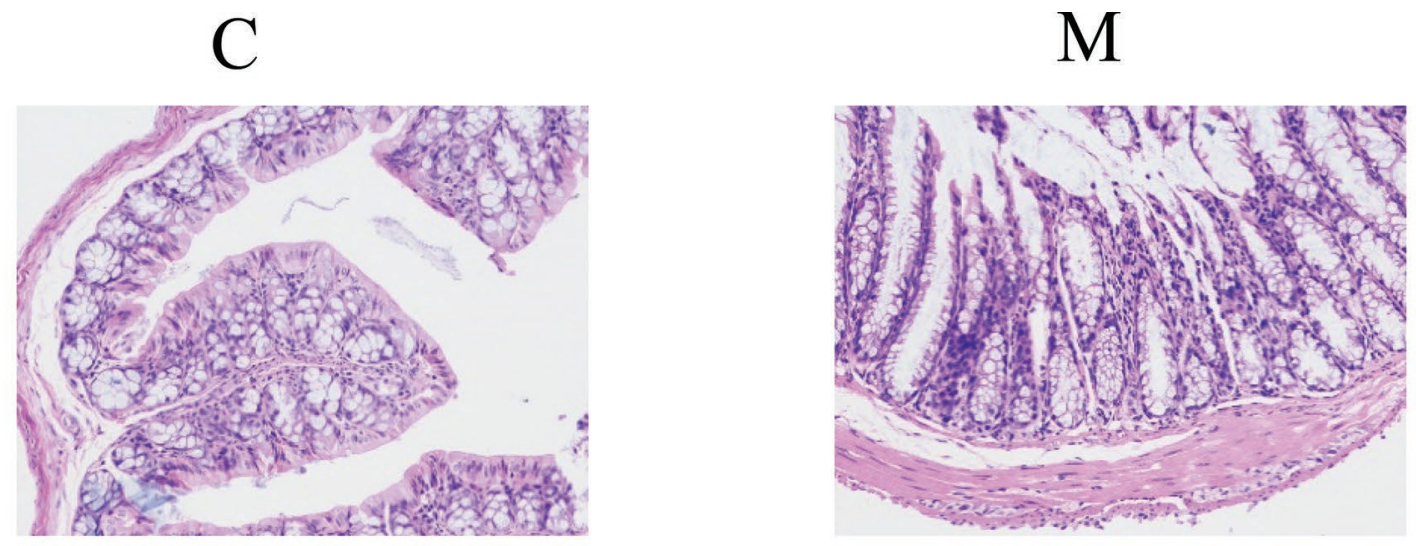

ZDY2013

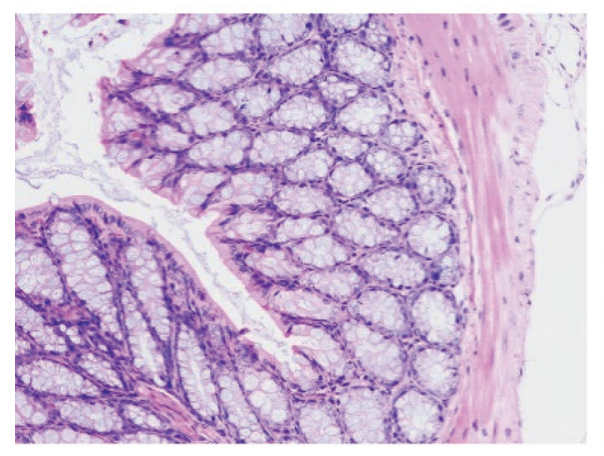

WLPL04

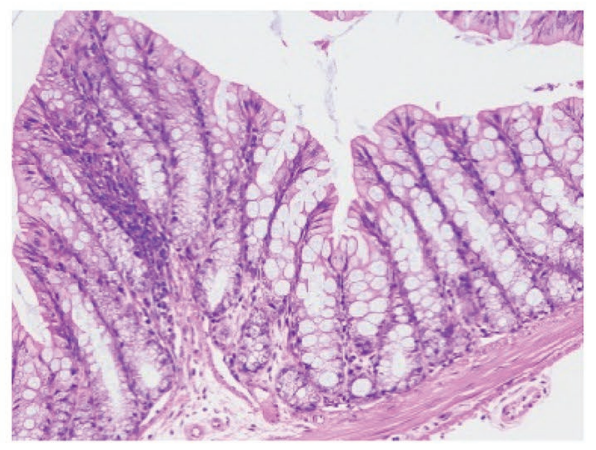

LGG

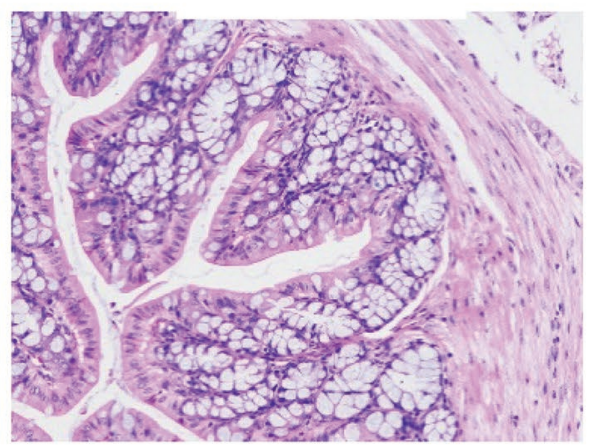

Ł

Figure 7. Effect of probiotics on colonic histopathology in mice model with $\beta$-LG-induced food allergy. Mice were treated from d 7 to 35 with $200 \mu \mathrm{L}$ of L. plantarum ZDY2013 (ZDY2013 group), L. plantarum WLPL04 (WLPL04 group), or L. rhamnosus GG (LGG group). 
A

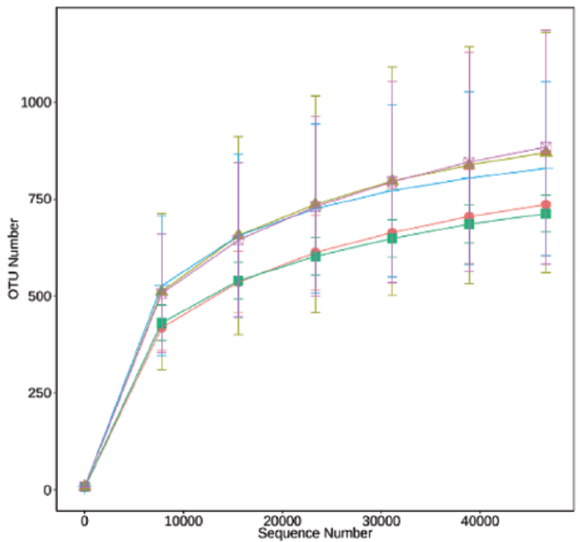

B
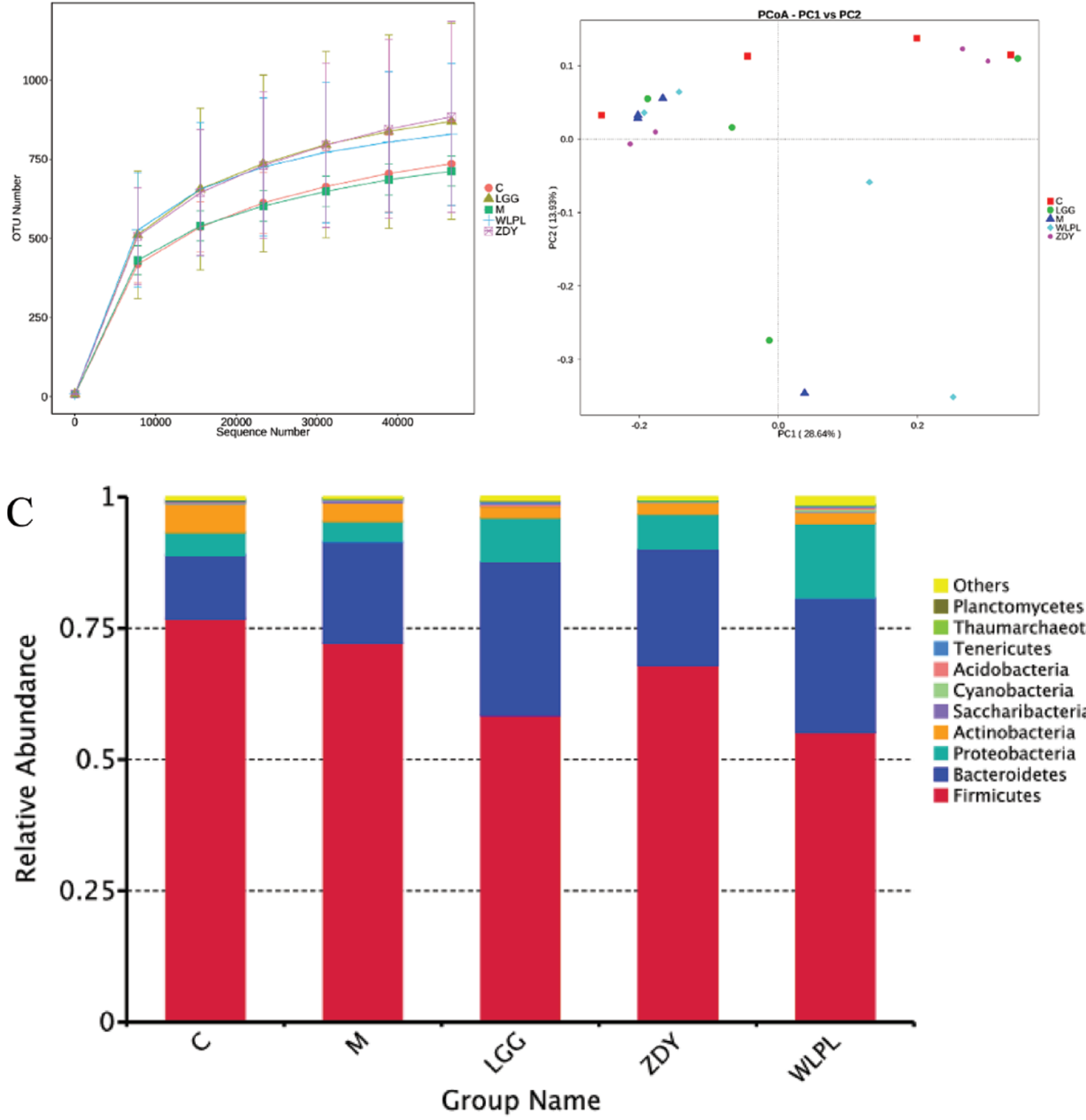

D

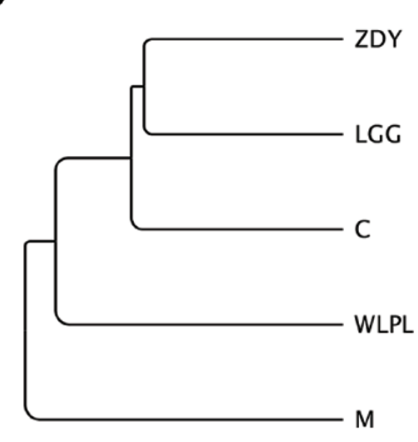

Unweighted Unifrac Distance

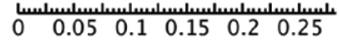

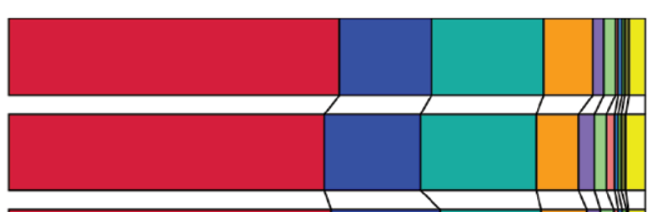

$\square$ Firmicutes

Proteobacteria

Bacteroidetes

Actinobacteria Acidobacteria $\square$ Tenericutes

$\square$ Gemmatimonadetes

$\square$ Chloroflexi

$\square$ Planctomycetes

$\square$ Verrucomicrobia

$\square$ Others

Figure 8. Probiotics modulates fecal microbiota composition in $\beta$-LG-sensitized mice. (A) Rarefaction curves of operational taxonomic units for each group. The center of the error bar is the arithmetic mean of the measured values, and the error bars represent the central value \pm SD. (B) Principal coordinates analysis (PCoA) of the mice intestinal microflora of each group. (C) Microbial composition of mice feces of each group in phylum level. (D) Unweighted pair-group method with arithmetic means clustering of the mice intestinal microflora of each group. L. plantarum ZDY2013 (ZDY group), L. rhamnosus GG (LGG group), L. plantarum WLPL04 (WLPL group), control (C group), and mock (M group). 
Table 2. Effects of $\beta$-LG-induced allergies on intestinal microbiota of mice at family and genus level ${ }^{1}$

\begin{tabular}{|c|c|c|c|c|c|}
\hline Item & \multicolumn{2}{|c|}{ M } & \multicolumn{2}{|c|}{$\mathrm{C}$} & $P$-value \\
\hline \multicolumn{6}{|l|}{ Family } \\
\hline Enterococcaceae & 0.042508 & 0.01422 & 0.010466 & 0.00349 & 0.017 \\
\hline Erysipelotrichaceae & 0.001977 & 0.00044 & 0.000906 & 0.0002 & 0.01 \\
\hline Clostridiales vadinBB60 group & 0.003628 & 0.00053 & 0.001372 & 0.00119 & 0.024 \\
\hline Enterococcus & 0.042503 & 0.01422 & 0.010466 & 0.00349 & 0.017 \\
\hline Rikenella & 0.007899 & 0.00282 & 0.000772 & 0.00037 & 0.014 \\
\hline Ruminiclostridium & 0.014126 & 0.0066 & 0.003065 & 0.00489 & 0.039 \\
\hline Unidentified Ruminococcaceae & 0.01052 & 0.005 & 0.001409 & 0.00116 & 0.033 \\
\hline Unidentified Lachnospiraceae & 0.00925 & 0.00347 & 0.002535 & 0.00344 & 0.033 \\
\hline Dorea & 0 & 0 & 0.000145 & 0.00018 & 0.206 \\
\hline Ralstonia & 0.00023 & 0.0003 & 0.000032 & 0.00006 & 0.281 \\
\hline
\end{tabular}

${ }^{1}$ Mice were randomly divided into a control group $(\mathrm{C})$ and sensitized group $(\mathrm{M})$. To induce an allergic response, mice were sensitized with 0.2 $\mathrm{mL}$ of $2 \mathrm{mg} / \mathrm{mL}$ allergen ( $1 \mathrm{~mL}$ of Freund's adjuvant and $1 \mathrm{~mL}$ of $2 \mathrm{mg} / \mathrm{mL} \beta-\mathrm{LG}$ ) by i.p. injection on $\mathrm{d} 7,14,21$, and 28 , and challenged twice with $\beta$-LG ( $5 \mathrm{mg} / \mathrm{mouse}$ ) on d 35. From d 7 to 35, mice from the control and sensitized groups received $200 \mu \mathrm{L}$ of sterile PBS.

the destruction of the gut barrier, and consequently prevented the penetration of harmful substances in the intestinal lumen and suppressed immune response.

The gastrointestinal microbiota of mammals exhibit 3 characteristics, namely high population density, wide diversity, and complexity of interactions (Zoetendal et al., 2004). The main functions of the microbiota include increasing the intestinal mucosal barrier, promoting immune system maturation, stimulating intestinal secretion of IgA, preventing the adhesion of pathogenic microorganisms, and participating in the formation of immune tolerance (Chow et al., 2010). Numerous studies have illustrated that intestinal microbes are closely related to allergic diseases (Salzman et al., 2010; Diesner et al., 2016) and the increasing susceptibility to allergic and autoimmune diseases (Cho and Blaser, 2012). Kirjavainen and Gibson (1999) reported that intestinal microorganisms can downregulate allergic inflammation by counterbalancing type Th2 cell responses and enhancing antigen exclusion through IgA response. Furthermore, recent studies suggested that microbiota composition could influence immune-

Table 3. The effect of Lactobacillus plantarum ZDY2013 (ZDY2013) on intestinal microbiota of mice at family and genus level ${ }^{1}$

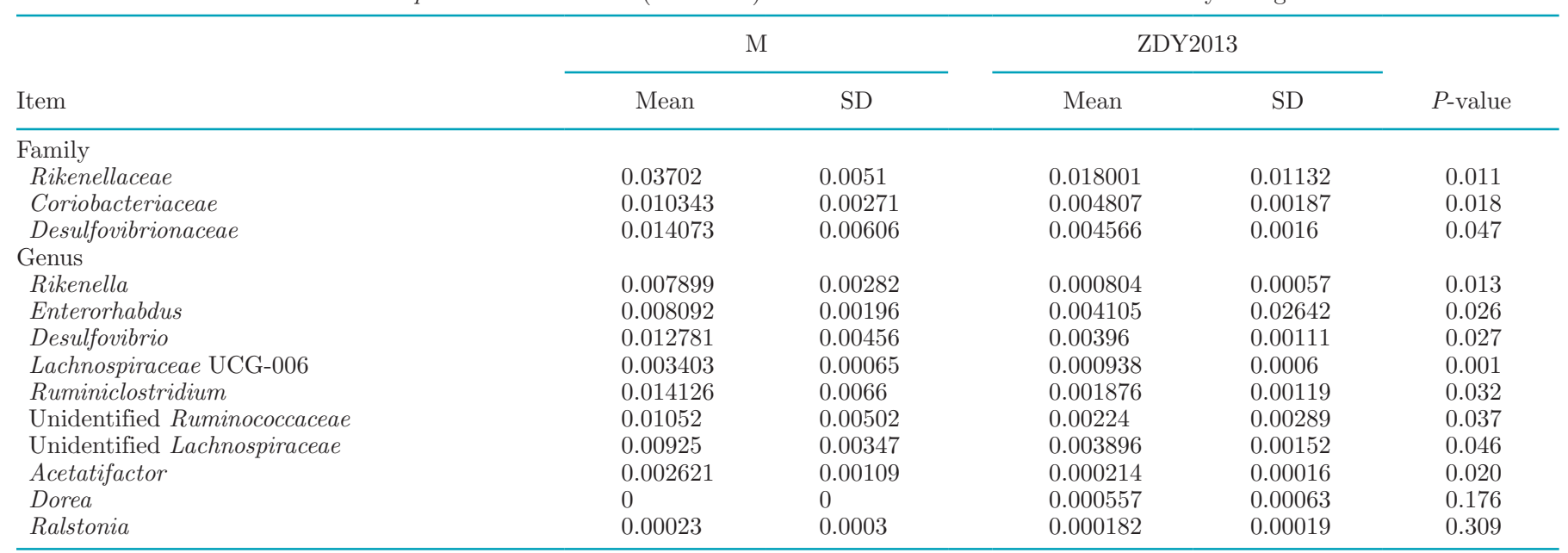

${ }^{1}$ Mice in the sensitized group (M) group were sensitized with $0.2 \mathrm{~mL}$ of $2 \mathrm{mg} / \mathrm{mL}$ allergen $(1 \mathrm{~mL}$ of Freund's adjuvant and $1 \mathrm{~mL}$ of $2 \mathrm{mg} / \mathrm{mL}$ $\beta$-LG) by i.p. injection on d 7, 14, 21, and 28 , and challenged twice with $\beta$-LG (5 mg/mouse) on d 35. From d 7 to 35 , mice in the ZDY2013group were administered $200 \mu \mathrm{L} /$ mouse of $L$. plantarum ZDY2013 by gavage, 4 times per week. 
Table 4. The effect of Lactobacillus plantarum WLPL04 on intestinal microbiota of mice at family and genus level ${ }^{1}$

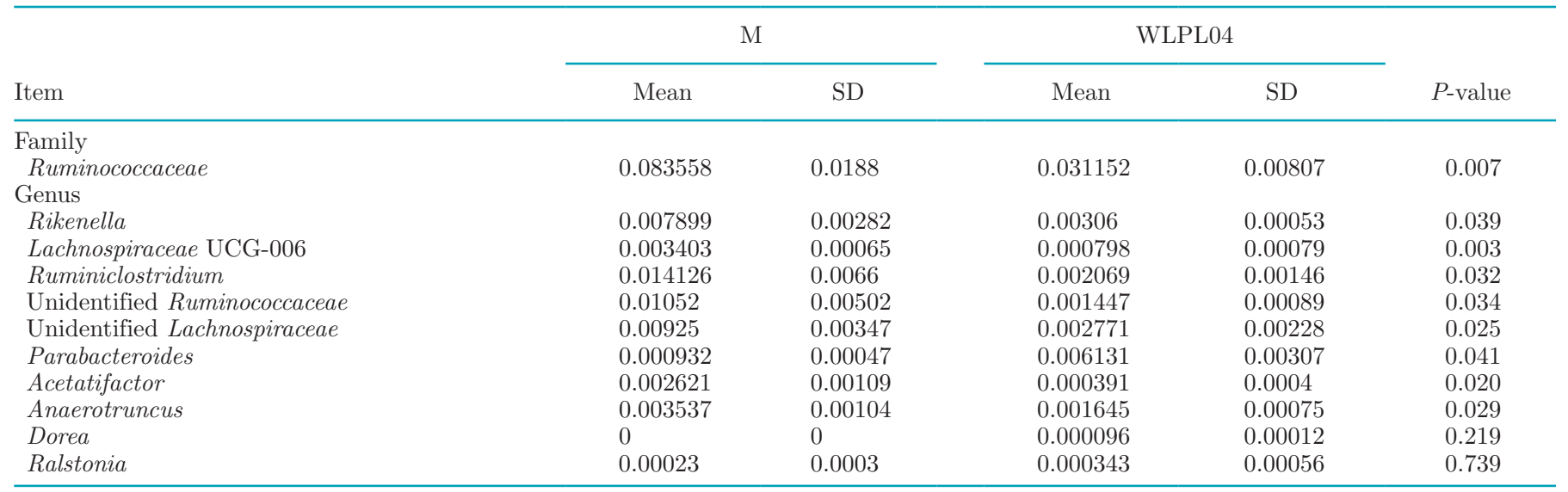

${ }^{1}$ Mice in the sensitized group (M) group were sensitized with $0.2 \mathrm{~mL}$ of $2 \mathrm{mg} / \mathrm{mL}$ allergen $(1 \mathrm{~mL}$ of Freund's adjuvant and $1 \mathrm{~mL}$ of $2 \mathrm{mg} / \mathrm{mL}$ $\beta$-LG) by i.p. injection on d $7,14,21$, and 28 , and challenged twice with $\beta$-LG $(5 \mathrm{mg} / \mathrm{mouse}$ ) on d 35 . From d 7 to 35 , mice in the WLPL04 group were administered $200 \mu \mathrm{L} /$ mouse of $L$. plantarum WLPL04 by gavage, 4 times per week.

mediated diseases, such as autoimmunity and allergy (Geuking et al., 2014).

Probiotics, which can regulate intestinal microbiota caused by allergies, are essential for preventing or alleviating allergic diseases. Kim et al. (2005) reported that Bifidobacterium bifidum BGN4 and Lactobacillus casei 911 may be useful probiotic bacteria for preventing allergy in mouse models. Harata et al. (2017) reported that L. rhamnosus GG (ATCC53103) and Lactobacillus gasseri TMC0356 can modulate gut microbiota to cure allergy caused by Japanese cedar pollinosis. Consistently, we found that lactobacilli can regulate the intestinal microbiota composition of $\beta$-LG-sensitized mice. A considerable increase in the Simpson index was observed in the sensitized group, and gut barrier function might have be impaired in sensitized mice. These phenomena possibly caused intestinal microecological imbalance, as identified through sequencing of $16 \mathrm{~S}$ rRNA gene, which was used to determine the effect of 3 strains of $\mathrm{Lac}$ tobacillus on $\beta$-LG-induced sensitized mice. Moreover, beneficial bacteria inherent in the intestinal tract may substantially decrease and some opportunistic bacteria may multiply. This result is similar to the study of Berni Canani et al. (2016), which showed that the microbiota of cow milk allergy infants is more diverse than that of healthy controls. The PCoA and UPGMA cluster analysis showed marked difference in microbiota between the ZDY2013 group and the sensitized group; these findings indicate that Lactobacillus markedly affects the intestinal microbiota structure of sensitized mice. Ruminococcaceae and Lachnospiraceae showed a significant increase in cow milk allergy guts (Berni Canani et al., 2016). Ruminococcus is positively correlated with inflammation-related diseases and Lachnospiraceae is strongly correlated in obese patients (Meehan and Beiko, 2014); we consistently found that ZDY2013 and WLPL04 considerably decreased the abundance of these 2 species after oral gavage through $t$-test analysis. Dorea can be significantly reduced in the gut microbiome of food-allergic infants and is closely related to the balance of $\mathrm{T}$ cells, thus suggesting its potential in preventing allergies (Savage et al., 2018). In addition, some literature reported that Dorea could bring about major changes in the intestinal microbiota after adding lactic acid bacteria (Chen et al., 2014; Nishida et al., 2017). By contrast, Ralstonia exerts proinflammatory effects in patients with Parkinson's syndrome (Keshavarzian et al., 2015) and is enriched in chronic rhinitis (Ramakrishnan et al., 2015), indicating its destructive effect on the host immune system. In our research, we did not detect Dorea in the gut microbiota of sensitized mice; therefore, we speculated that probiotics may affect the production of intestinal metabolites, such as short-chain fatty acids, by regulating the structure of the intestinal microbiota and promoting the maturation of the immune system.

\section{CONCLUSIONS}

In conclusion, the possible mechanism of the $3 \mathrm{Lac}$ tobacillus strains that alleviated $\beta$-LG-induced allergy involved 3 main aspects. All 3 strains of Lactobacillus regulated intestinal immune balance; in particular, LGG and ZDY2013 inhibited Th2 responses by inducing differentiation of Treg cells or Th1 cells. However, LGG and ZDY2013 considerably increased the relative 
expression of tight junction proteins, enhanced intestinal barrier function, and relieved allergies. In addition, ZDY2013 and WLPL04 regulated the structure of intestinal microbiota to affect allergies.

\section{ACKNOWLEDGMENTS}

We sincerely thank the editor and reviewers for their contributions and suggestions. All procedures involving animals were approved by the Animal Care Review Committee (approval number 0064257), Nanchang University, Jiangxi, China, and adhered to the institutional animal care committee guidelines. This work was supported by National Natural Science Foundation of China (Nanchang, China; 81760102 and 31770133). The authors declare that the research was conducted in the absence of any commercial or financial relationships that could be construed as a potential conflict of interest.

\section{REFERENCES}

Akdis, M., S. Burgler, R. Crameri, T. Eiwegger, H. Fujita, E. Gomez, S. Klunker, N. Meyer, L. O'Mahony, and O. Palomares. 2011. Interleukins, from 1 to 37 , and interferon- $\gamma$ : Receptors, functions, and roles in diseases. J. Allergy Clin. Immunol. 127:701-721. https: //doi.org/10.1016/j.jaci.2010.11.050.

Artis, D. 2008. Epithelial-cell recognition of commensal bacteria and maintenance of immune homeostasis in the gut. Nat. Rev. Immunol. 8:411.

Bae, C. J., J. W. Lee, S. B. Shim, S. W. Jee, S. H. Lee, J. M. Woo, C. K. Lee, and D. Y. Hwang. 2011. GATA binding protein 3 overexpression and suppression significantly contribute to the regulation of allergic skin inflammation. Int. J. Mol. Med. 28:171-179.

Bae, M.-J., H. S. Shin, H.-J. See, S. Y. Jung, D.-A. Kwon, and D.-H. Shon. 2016. Baicalein induces $\mathrm{CD} 4^{+}$Foxp $3^{+} \mathrm{T}$ cells and enhances intestinal barrier function in a mouse model of food allergy. Sci. Rep. 6:32225.

Berni Canani, R., N. Sangwan, A. T. Stefka, R. Nocerino, L. Paparo, R. Aitoro, A. Calignano, A. A. Khan, J. A. Gilbert, and C. R. Nagler. 2016. Lactobacillus rhamnosus GG-supplemented formula expands butyrate-producing bacterial strains in food allergic infants. ISME J. 10:742.

Braun-Fahrländer, C., and E. Von Mutius. 2011. Can farm milk consumption prevent allergic diseases? Clin. Exp. Allergy 41:29-35.

Caporaso, J. G., C. L. Lauber, W. A. Walters, D. Berg-Lyons, C. A. Lozupone, P. J. Turnbaugh, N. Fierer, and R. Knight. 2011. Global patterns of $16 \mathrm{~S}$ rRNA diversity at a depth of millions of sequences per sample. Proc. Natl. Acad. Sci. USA 108(Suppl. 1):4516-4522.

Chahine, B. G., and S. L. Bahna. 2010. The role of the gut mucosal immunity in the development of tolerance versus development of allergy to food. Curr. Opin. Allergy Clin. Immunol. 10:394-399.

Chen, D., Z. Yang, X. Chen, Y. Huang, B. Yin, F. Guo, H. Zhao, T. Zhao, H. Qu, J. Huang, Y. Wu, and R. Gu. 2014. The effect of Lactobacillus rhamnosus hsryfm 1301 on the intestinal microbiota of a hyperlipidemic rat model. BMC Complement. Altern. Med. $14: 386$.

Chistiakov, D. A., Y. V. Bobryshev, E. Kozarov, I. A. Sobenin, and A. N. Orekhov. 2015. Intestinal mucosal tolerance and impact of gut microbiota to mucosal tolerance. Front. Microbiol. 5:781.

Cho, I., and M. J. Blaser. 2012. The human microbiome: At the interface of health and disease. Nat. Rev. Genet. 13:260.
Chow, J., S. M. Lee, Y. Shen, A. Khosravi, and S. K. Mazmanian. 2010. Host-bacterial symbiosis in health and disease. Adv. Immunol. 107:243-274.

Cole, J. R., B. Chai, R. J. Farris, Q. Wang, S. A. Kulam, D. M. McGarrell, G. M. Garrity, and J. M. Tiedje. 2005. The Ribosomal Database Project (RDP-II): Sequences and tools for high-throughput rRNA analysis. Nucleic Acids Res. 33(Suppl. 1):D294-D296.

Cottrez, F., S. D. Hurst, R. L. Coffman, and H. Groux. 2000. T regulatory cells 1 inhibit a Th2-specific response in vivo. J. Immunol. 165:4848.

Delcenserie, V., D. Martel, M. Lamoureux, J. Amiot, Y. Boutin, and D. Roy. 2008. Immunomodulatory effects of probiotics in the intestinal tract. Curr. Issues Mol. Biol. 10:37-54.

Diesner, S. C., C. Bergmayr, B. Pfitzner, V. Assmann, D. Krishnamurthy, P. Starkl, D. Endesfelder, M. Rothballer, G. Welzl, T. Rattei, T. Eiwegger, Z. Szepfalusi, H. Fehrenbach, E. Jensen-Jarolim, A. Hartmann, I. Pali-Scholl, and E. Untersmayr. 2016. A distinct microbiota composition is associated with protection from food allergy in an oral mouse immunization model. Clin. Immunol. $173: 10-18$

Fábrega, M. J., L. Aguilera, R. Giménez, E. Varela, M. Alexandra Cañas, M. Antolín, J. Badía, and L. Baldomà. 2016. Activation of immune and defense responses in the intestinal mucosa by outer membrane vesicles of commensal and probiotic Escherichia coli Strains. Front. Microbiol. 7:705.

Forsythe, P. 2011. Probiotics and lung diseases. Chest 139:901-908.

Fu, L., J. Song, C. Wang, S. Fu, and Y. Wang. 2017. Bifidobacterium infantis potentially alleviates shrimp tropomyosin-induced allergy by tolerogenic dendritic cell-dependent induction of regulatory $\mathrm{T}$ cells and alterations in gut microbiota. Front. Immunol. 8:1536.

Geuking, M. B., K. Yasmin, R. Sandra, and K. D. Mccoy. 2014. The interplay between the gut microbiota and the immune system. Gut Microbes 5:411-418.

Gordon, B. R. 2011. The allergic march: Can we prevent allergies and asthma? Otolaryngol. Clin. North Am. 44:765-777.

Gri, G., S. Piconese, B. Frossi, V. Manfroi, S. Merluzzi, C. Tripodo, A. Viola, S. Odom, J. Rivera, M. P. Colombo, and C. E. Pucillo. 2008. $\mathrm{CD} 4^{+} \mathrm{CD} 25^{+}$regulatory $\mathrm{T}$ cells suppress mast cell degranulation and allergic responses through OX40-OX40L Interaction. Immunity 29:771-781.

Harata, G., H. Kumar, F. He, K. Miyazawa, K. Yoda, M. Kawase, A. Kubota, M. Hiramatsu, S. Rautava, and S. Salminen. 2017. Probiotics modulate gut microbiota and health status in Japanese cedar pollinosis patients during the pollen season. Eur. J. Nutr. 56:2245-2253

He, H., R. Li, Y. Chen, P. Pan, W. Tong, X. Dong, Y. Chen, and D. Yu. 2017. Integrated DNA and RNA extraction using magnetic beads from viral pathogens causing acute respiratory infections. Sci. Rep. 7:45199.

Huang, C.-H., D.-Z. Liu, and T.-R. Jan. 2010. Diosgenin, a plantderived sapogenin, enhances regulatory T-cell immunity in the intestine of mice with food allergy. J. Nat. Prod. 73:1033-1037.

Huang, C.-H., C.-C. Shen, Y.-C. Liang, and T.-R. Jan. 2016a. The probiotic activity of Lactobacillus murinus against food allergy. J. Funct. Foods 25:231-241.

Huang, R., M. Pan, C. Wan, N. P. Shah, X. Tao, and H. Wei. 2016b. Physiological and transcriptional responses and cross protection of Lactobacillus plantarum ZDY2013 under acid stress. J. Dairy Sci. 99:1002-1010.

Huang, R., X. Tao, C. Wan, S. Li, H. Xu, F. Xu, N. P. Shah, and H. Wei. 2015. In vitro probiotic characteristics of Lactobacillus plantarum ZDY 2013 and its modulatory effect on gut microbiota of mice. J. Dairy Sci. 98:5850-5861.

Hyung, K. E., B. S. Moon, B. Kim, E. S. Park, S.-Y. Park, and K. W. Hwang. 2017. Lactobacillus plantarum isolated from kimchi suppress food allergy by modulating cytokine production and mast cells activation. J. Funct. Foods 29:60-68.

Jiang, M., F. Zhang, C. Wan, Y. Xiong, N. P. Shah, H. Wei, and X. Tao. 2016. Evaluation of probiotic properties of Lactobacillus 
plantarum WLPL04 isolated from human breast milk. J. Dairy Sci. 99:1736-1746.

Jo, J., J. Garssen, L. Knippels, and E. Sandalova. 2014. Role of cellular immunity in cow's milk allergy: pathogenesis, tolerance induction, and beyond. Mediators Inflamm. 2014:249784.

Kaminogawa, S., S. Hachimura, and H. N. A. Totsuka. 1999. Food allergens and mucosal immune systems with special reference to recognition of food allergens by gut-associated lymphoid tissue. Allergol. Int. 48:15-23.

Keshavarzian, A., J. Green Stefan, A. Engen Phillip, M. Voigt Robin, A. Naqib, B. Forsyth Christopher, E. Mutlu, and M. Shannon Kathleen. 2015. Colonic bacterial composition in Parkinson's disease. Mov. Disord. 30:1351-1360.

Kim, H., K. Kwack, D. Y. Kim, and G. E. Ji. 2005. Oral probiotic bacterial administration suppressed allergic responses in an ovalbumin-induced allergy mouse model. FEMS Immunol. Med. Microbiol. 45:259-267.

Kim, H.-J., Y.-J. Kim, S.-H. Lee, J. Yu, S. K. Jeong, and S.-J. Hong. 2014. Effects of Lactobacillus rhamnosus on allergic march model by suppressing Th2, Th17, and TSLP responses via CD $4^{+} \mathrm{CD} 25^{+}$ Foxp $3^{+}$Tregs. Clin. Immunol. 153:178-186.

Kirjavainen, P. V., E. Apostolou, S. J. Salminen, and E. Isolauri. 1999. New aspects of probiotics - A novel approach in the management of food allergy. Allergy 54:909-915.

Kirjavainen, P. V., and G. R. Gibson. 1999. Healthy gut microflora and allergy: Factors influencing development of the microbiota. Ann. Med. 31:288-292.

Kobayashi, H., P. Kanmani, T. Ishizuka, A. Miyazaki, J. Soma, L. Albarracin, Y. Suda, T. Nochi, H. Aso, N. Iwabuchi, J. Z. Xiao, T. Saito, J. Villena, and H. Kitazawa. 2017. Development of an in vitro immunobiotic evaluation system against rotavirus infection in bovine intestinal epitheliocytes. Benef. Microbes 8:309-321.

Kozakova, H., M. Schwarzer, L. Tuckova, D. Srutkova, E. Czarnowska, I. Rosiak, T. Hudcovic, I. Schabussova, P. Hermanova, and Z. Zakostelska. 2016. Colonization of germ-free mice with a mixture of three Lactobacillus strains enhances the integrity of gut mucosa and ameliorates allergic sensitization. Cell. Mol. Immunol. 13:251-262.

Kwon, H.-K., C.-G. Lee, J.-S. So, C.-S. Chae, J.-S. Hwang, A. Sahoo, J. H. Nam, J. H. Rhee, K.-C. Hwang, and S.-H. Im. 2010. Generation of regulatory dendritic cells and $\mathrm{CD} 4^{+} \mathrm{Foxp}^{+} \mathrm{T}$ cells by probiotics administration suppresses immune disorders. Proc. Natl. Acad. Sci. USA 107:2159-2164.

Li, X.-M., B. H. Schofield, C.-K. Huang, G. I. Kleiner, and H. A. Sampson. 1999. A murine model of IgE-mediated cow's milk hypersensitivity. J. Allergy Clin. Immunol. 103:206-214.

Lin, Z.-W., L.-X. Wu, Y. Xie, X. Ou, P.-K. Tian, X.-P. Liu, J. Min, J. Wang, R.-F. Chen, Y.-J. Chen, C. Liu, H. Ye, and Q.-J. Ou. 2015. The expression levels of transcription factors T-bet, GATA$3, \mathrm{ROR} \gamma \mathrm{t}$ and FOXP3 in peripheral blood lymphocyte (PBL) of patients with liver cancer and their significance. Int. J. Med. Sci. $12: 7-16$.

Järvinen, K. M., G. N. Konstantinou, M. Pilapil, M. C. Arrieta, S. Noone, H. A. Sampson, J. Meddings, and A. Nowak-Wegrzyn. 2013. Intestinal permeability in children with food allergy on specific elimination diets. Pediatr. Allergy Immunol. 24:589-595.

Meehan, C. J., and R. G. Beiko. 2014. A phylogenomic view of ecological specialization in the Lachnospiraceae, a Family of digestive tract-associated bacteria. Genome Biol. Evol. 6:703-713.

Miraglia Del Giudice, M., C. Indolfi, M. Capasso, N. Maiello, F. Decimo, and G. Ciprandi. 2017. Bifidobacterium mixture (B. longum BB536, B. infantis M-63, B. breve M-16V) treatment in children with seasonal allergic rhinitis and intermittent asthma. Ital. J. Pediatr. 43:25

Neau, E., J. Delannoy, C. Marion, C.-H. Cottart, C. Labellie, S. Holowacz, M.-J. Butel, N. Kapel, and A.-J. Waligora-Dupriet. 2016. Three novel candidate probiotic strains with prophylactic properties in a murine model of cow's milk allergy. Appl. Environ. Microbiol. 82:1722-1733.
Nébot-Vivinus, M., C. Harkat, H. Bzioueche, C. Cartier, R. PlichonDainese, L. Moussa, H. Eutamene, D. Pishvaie, S. Holowacz, C. Seyrig, T. Piche, and V. Theodorou. 2014. Multispecies probiotic protects gut barrier function in experimental models. World J. Gastroenterol. 20:6832-6843.

Nieuwenhuizen, N. E., and A. L. Lopata. 2005. Fighting food allergy: Current approaches. Ann. N. Y. Acad. Sci. 1056:30-45.

Nishida, K., D. Sawada, T. Kawai, Y. Kuwano, S. Fujiwara, and K. Rokutan. 2017. Para-psychobiotic Lactobacillus gasseri CP2305 ameliorates stress-related symptoms and sleep quality. J. Appl. Microbiol. 123:1561-1570.

Ouwehand, A. C. 2007. Antiallergic effects of probiotics. J. Nutr. 137(Suppl 2):794S-797S.

Pellerin, L., J. A. Jenks, P. Bégin, R. Bacchetta, and K. C. Nadeau. 2014. Regulatory $\mathrm{T}$ cells and their roles in immune dysregulation and allergy. Immunol. Res. 58:358-368.

Penders, J., K. Gerhold, E. E. Stobberingh, C. Thijs, K. Zimmermann, S. Lau, and E. Hamelmann. 2013. Establishment of the intestinal microbiota and its role for atopic dermatitis in early childhood. J. Allergy Clin. Immunol. 132:601-607.

Perrier, C., and B. Corthesy. 2011. Gut permeability and food allergies. Clin. Exp. Allergy 41:20-28.

Pessi, T., Y. Sutas, M. Hurme, and E. Isolauri. 2000. Interleukin-10 generation in atopic children following oral Lactobacillus rhamnosus GG. Clin. Exp. Allergy 30:1804-1808.

Pohjavuori, E., M. Viljanen, R. Korpela, M. Kuitunen, M. Tiittanen, O. Vaarala, and E. Savilahti. 2004. Lactobacillus GG effect in increasing IFN-gamma production in infants with cow's milk allergy. J. Allergy Clin. Immunol. 114:131-136.

Ramakrishnan, V. R., L. J. Hauser, L. M. Feazel, D. Ir, C. E. Robertson, and D. N. Frank. 2015. Sinus microbiota varies among chronic rhinosinusitis phenotypes and predicts surgical outcome. J. Allergy Clin. Immunol. 136:334-42.e1.

Salzman, N. H., K. Hung, D. Haribhai, H. Chu, J. Karlsson-Sjöberg, E. Amir, P. Teggatz, M. Barman, M. Hayward, D. Eastwood, M Stoel, Y. Zhou, E. Sodergren, G. M. Weinstock, C. L. Bevins, C. B. Williams, and N. A. Bos. 2010. Enteric defensins are essential regulators of intestinal microbial ecology. Nat. Immunol. 11:76.

Savage, J. H., K. A. Lee-Sarwar, J. Sordillo, S. Bunyavanich, Y. Zhou, G. O'Connor, M. Sandel, L. B. Bacharier, R. Zeiger, E. Sodergren, D. M. Weinstock, D. R. Gold, S. T. Weiss, and A. A. Litonjua. 2018. A prospective microbiome-wide association study of food sensitization and food allergy in early childhood. Allergy 73:145152

Schiavi, E., B. Barletta, C. Butteroni, S. Corinti, M. Boirivant, and G. Di Felice. 2011. Oral therapeutic administration of a probiotic mixture suppresses established Th2 responses and systemic anaphylaxis in a murine model of food allergy. Allergy 66:499-508.

Shandilya, U. K., A. Sharma, R. Kapila, and V. K. Kansal. 2016. Probiotic Dahi containing Lactobacillus acidophilus and Bifidobacterium bifidum modulates immunoglobulin levels and cytokines expression in whey proteins sensitised mice. J. Sci. Food Agric. 96:3180-3187.

Slack, E., S. Hapfelmeier, B. Stecher, Y. Velykoredko, M. Stoel, M. A. Lawson, M. B. Geuking, B. Beutler, T. F. Tedder, and W.-D. Hardt. 2009. Innate and adaptive immunity cooperate flexibly to maintain host-microbiota mutualism. Science 325:617-620.

Strachan, D. P. 1989. Hay fever, hygiene, and household size. BMJ 299:1259

Tang, M. L. K., A.-L. Ponsonby, F. Orsini, D. Tey, M. Robinson, E. L. Su, P. Licciardi, W. Burks, and S. Donath. 2015. Administration of a probiotic with peanut oral immunotherapy: A randomized trial. J. Allergy Clin. Immunol. 135:737-44.e8.

Tlaskalová-Hogenová, H., R. Štěpánková, H. Kozáková, T. Hudcovic, L. Vannucci, L. Tučková, P. Rossmann, T. Hrnčřr, M. Kverka, and Z. Zákostelská. 2011. The role of gut microbiota (commensal bacteria) and the mucosal barrier in the pathogenesis of inflammatory and autoimmune diseases and cancer: contribution of germ-free and gnotobiotic animal models of human diseases. Cell. Mol. Immunol. 8:110. 
US National Institutes of Health. 1996. Subject: Revision of the Guide for the Care and Use of Laboratory Animals. NIH Publication $85-23$.

van Ree, R., L. Hummelshøj, M. Plantinga, L. K. Poulsen, and E. Swindle. 2014. Allergic sensitization: Host-immune factors. Clin. Transl. Allergy 4:12.

Vanderpool, C., F. Yan, and D. B. Polk. 2008. Mechanisms of probiotic action: Implications for therapeutic applications in inflammatory bowel diseases. Inflamm. Bowel Dis. 14:1585-1596.

Vanhaecke, T., P. Aubert, P. A. Grohard, T. Durand, P. Hulin, P. Paul-Gilloteaux, A. Fournier, F. Docagne, A. Ligneul, and C. Fressange-Mazda. 2017. L. fermentum CECT 5716 prevents stressinduced intestinal barrier dysfunction in newborn rats. Neurogastroenterol. Motil. 29:6-7.

Wang, H., X. Ni, X. Qing, L. Liu, J. Xin, M. Luo, A. Khalique, Y. Dan, K. Pan, B. Jing, and D. Zeng. 2018. Probiotic Lactobacillus johnsonii BS15 improves blood parameters related to immunity in broilers experimentally infected with subclinical necrotic enteritis. Front. Microbiol. 9:49.

Yang, B., L. Xiao, S. Liu, X. Liu, Y. Luo, Q. Ji, P. Yang, and Z. Liu. 2017. Exploration of the effect of probiotics supplementation on intestinal microbiota of food allergic mice. Am. J. Transl. Res. 9:376-385

Zhang, J., H. Su, Q. Li, H. Wu, M. Liu, J. Huang, M. Zeng, Y. Zheng, and X. Sun. 2017. Oral administration of Clostridium butyricum CGMCC0313-1 inhibits $\beta$-lactoglobulin-induced intestinal anaphylaxis in a mouse model of food allergy. Gut Pathog. 9:11.

Zoetendal, E. G., C. T. Collier, S. Koike, R. I. Mackie, and H. R. Gaskins. 2004. Molecular ecological analysis of the gastrointestinal microbiota: A Review. J. Nutr. 134:465-472. 